\title{
Síntesis, actividad antibacteriana e interacción del ADN con complejos de inclusión entre compuestos lantánidos y $\beta$-ciclodextrina
}

\section{Synthesis, antibacterial activity and interaction of DNA with lanthanide- $\beta$-cyclodextrin inclusion complexes}

\author{
Angélica María Mayor-Rivera a \\ Alberto Aragón-Muriel b \\ Dorian Polo-Cerón c*
}

Fecha de Recepción: 11 - oct. - 2017.

Fecha de Aceptación: 5 - may. - 2018.

\begin{abstract}
Resumen
En este trabajo se han sintetizado complejos de lantánidos a partir de los cloruros de La(III), Ce(III), Sm (III) e Yb(III) con ligandos cinamato, presentando coordinación bidentada entre el grupo carboxilo del ligando y el metal lantánido. Estos compuestos se utilizaron como huéspedes de la $\beta$-ciclodextrina con el fin de obtener nuevos complejos de inclusión mediante el método de co-precipitación, utilizando N,N-dimetilformamida como disolvente. Los productos de inclusión obtenidos fueron caracterizados mediante espectroscopía IR-ATR, Raman, UV-vis, RMN ${ }^{1} \mathrm{H}$ y ${ }^{13} \mathrm{C}$, DRX, TGA, DSC, análisis elemental y complexometría con EDTA. Se realizaron pruebas de actividad antibacteriana empleando 6 cepas ATTC (S. aureus ATCC 25923, S. aureus ATCC 29213, E. coli ATCC 25922, P. aeruginosa ATCC 27853, S. Typhimurium ATCC 14028 y K. pneumoniae ATCC BAA-2146) mediante el método de microdilución con caldo Mueller-Hinton; los resultados de actividad biológica para los complejos lantánidos permitieron evidenciar el efecto sinérgico entre el catión lantánido y el ligando cinamato. Igualmente, para los complejos de inclusión se observó una disminución de la concentración mínima inhibitoria (CMI) respecto a los complejos lantánidos iniciales. Los resultados obtenidos con el ADN de timo de ternera y el ADN plasmídico pBR322 permiten proponer una interacción electrostática entre los complejos evaluados y la estructura molécular del ADN.
\end{abstract}

Palabras clave: actividad antibacteriana, complejos de inclusión, complejos lantánidos, interacción con ADN.

a Química. Departamento de Química, Universidad del Valle, Santiago de Cali, Calle 13 No. 100-00 Cali, Colombia (76000)

b Químico, MSc. Departamento de Química, Universidad del Valle, Santiago de Cali, Calle 13 No. 100-00 Cali, Colombia (76000)

c Químico, PhD. Departamento de Química, Universidad del Valle, Santiago de Cali, Calle 13 No. 100-00 Cali, Colombia (76000)

* dorian.polo@correounivalle.edu.co 


\begin{abstract}
In this work, lanthanide complexes were synthesized starting from the corresponding La (III), Ce (III), Sm (III) and $\mathrm{Yb}$ (III) chlorides and cinnamate ligands which present bidentate coordination between the carboxyl group of the ligand and the lanthanide metal. These compounds were used as hosts of $\beta$-cyclodextrin to obtain new inclusion complexes by a co-precipitation method using N,N-dimethylformamide as solvent. The inclusion products were characterized by IR-ATR spectroscopy, Raman, UV-vis, ${ }^{1} \mathrm{H}$ and ${ }^{13} \mathrm{C}$ NMR, XRD, TGA-DSC, elemental analysis and EDTA complexometry. Antibacterial activity tests were performed using six ATTC strains (S. aureus ATCC 25923, S. aureus ATCC 29213, E. coli ATCC 25922, $P$. aeruginosa ATCC 27853, S. Typhimurium ATCC 14028 and $K$. pneumoniae ATCC BAA-2146) by the microdilution method with Mueller-Hinton broth. The results of the biological activity for the lanthanide complexes showed the synergistic effect between the lanthanide cation and the cinnamate ligand. For the inclusion complexes, a decrease of the minimum inhibitory concentration (MIC) was observed with respect to the initial lanthanide complexes. The results obtained with the bovine thymus DNA and the plasmid pBR322 DNA allow to propose an electrostatic interaction between the evaluated complexes and the molécular structure of the DNA.
\end{abstract}

Key words: antibacterial activity, inclusion complexes, interaction with DNA, lanthanide complexes.

\section{INTRODUCCIÓN}

Desde el descubrimiento de la penicilina y su producción en masa, ha transcurrido más de medio siglo, y durante este tiempo se han desarrollado una gran cantidad de medicamentos para ser utilizados en el tratamiento de enfermedades causadas por bacterias [1]. Debido a la problemática actual frente a bacterias multirresistentes a fármacos de primera línea, es necesario el descubrimiento de nuevas moléculas que puedan ser utilizadas como antibióticos. Una de ellas es el ácido cinámico, que naturalmente se extrae del aceite de canela y se utiliza ampliamente como aditivo en alimentos, cosméticos y fragancias [2-4]. Actualmente, se estudian sus propiedades farmacéuticas en vista de su probada actividad inhibitoria frente a diferentes cepas bacterianas y hongos [5-10]. Dicha actividad antimicrobiana puede provenir de las características estructurales del compuesto como el doble enlace (C $=\mathrm{C})$ y el grupo carboxilo, que le confieren carácter hidrófobo a la molécula para que pueda interactuar sobre las proteínas en las bacterias $[5,9,11]$, pues el primero podría formar complejos $\pi$ con aminoácidos aromáticos, mientras que el segundo podría interactuar con aminoácidos de carácter básicos.

Recientes estudios de complejos metálicos con ligandos que contienen anillos aromáticos han presentado resultados prometedores de actividad antibacteriana y antifúngica [12,13], demostrando que, por lo general, la presencia del metal mejora la actividad en comparación a los ligandos libres, muchas veces debido a que la quelación aumenta la deslocalización de electrones en todo el sistema quelante y mejora la lipofilicidad que puede conducir a la ruptura de la barrera de permeabilidad celular, retrasando los procesos celulares normales [14]. Trabajos realizados en nuestro grupo de investigación han demostrado que compuestos lantánidos derivados del ácido cinámico presentan actividad biológica frente a cepas fúngicas y parasitarias $[15,16]$, sin embargo, en la actualidad el uso de estos compuestos es limitado como consecuencia de su poca solubilidad en medios acuosos. Una solución plausible para mejorar la solubilidad y actividad biológica, de los compuestos anteriormente mencionados, es la obtención de complejos de inclusión entre los complejos lantánidos (huésped) y la $\beta$-ciclodextrina (anfitrión). Debido a las características que confieren los complejos tipo anfitrión-huésped con ciclodextrinas, es posible mejorar la solubilidad de los complejos lantánidos en solventes polares. La conformación geométrica en forma de toroide de la $\beta$-ciclodextrina $(\beta-C D)$, permite que la cavidad interna (al ser hidrófoba por los enlaces glucosídicos) pueda interaccionar con la molécula huésped, y la cavidad externa (al ser hidrofílica por los grupos hidroxilos presentes) facilite el aumento de la solubilidad de los compuestos.

Se ha reportado la síntesis de diferentes compuestos de inclusión utilizando moléculas huésped como, piroxicam, dexametasona, cefalospo- 
rinas, nimesulida, hidrocortisona, antimoniato de meglumina y carvacrol [17-20], en este último caso la encapsulación mejoró la solubilidad en medio acuoso del fármaco, logrando disminuir la cantidad de compuesto necesario para obtener la inhibición del crecimiento de las dos cepas bacterianas evaluadas (S. Typhimurium y E. coli K12). Además, los complejos obtenidos mejoraron su estabilidad, evitando su degradación por la luz durante el almacenamiento [19].

En este trabajo se describe la síntesis de una serie de nuevos complejos de inclusión parcial y/o asociación con la $\beta$-CD utilizando complejos lantánidos como moléculas huésped. Se evaluó la actividad antibacteriana de los compuestos libres, así como los de inclusión frente a cepas bacterianas ATTC gram-negativas y gram-positivas, empleando el método de microdilución con platos de 96 pocillos y caldo Mueller-Hinton. La posible interacción entre los complejos de inclusión y la molécula de ADN fue evaluada mediante experimentos de UV-Vis y electroforesis.

\section{METODOLOGÍA}

Los ácidos $p$-clorocinámico y $p$-metoxicinámico, y las sales $\mathrm{LnCl}_{3} \cdot \mathrm{xH}_{2} \mathrm{O}(\mathrm{Ln}=\mathrm{La}, \mathrm{Ce}, \mathrm{Sm}$, $\mathrm{Yb}$ ) utilizadas, son reactivos comerciales de la marca Alfa Aesar, los cuales fueron empleados directamente sin tratamiento alguno. Los espectros infrarrojos reportados se midieron en un espectrofotómetro SHIMADZU-IR Affinity-1 con aditamento ATR en un rango de 600-4000 $\mathrm{cm}^{-1}$. Los espectros raman reportados fueron registrados en un espectrofotómetro DXR Smart
Raman en un rango de 200-3400 $\mathrm{cm}^{-1}$ utilizando laser de $785 \mathrm{~nm}$ y corrección de fluorescencia. Los espectros $\mathrm{RMN}{ }^{1} \mathrm{H}$ y ${ }^{13} \mathrm{C}$ se tomaron en un espectrofotómetro Bruker Avance 400 II utilizando DMSO- $\mathrm{d}_{6}$ a temperatura ambiente. El análisis elemental (C, H) se llevó a cabo en un analizador elemental serie Flash EA 1112, y el contenido de iones lantánidos, $\mathrm{Ln}(\mathrm{III})$, fue determinado mediante valoración con EDTA. Los termogramas fueron obtenidos en un equipo Mettler Toledo TGA/DSC1 STARe System (de análisis simultaneo), se llevó a cabo el calentamiento de 30-550 ${ }^{\circ} \mathrm{C}$ a razón de $10{ }^{\circ} \mathrm{C} / \mathrm{min}$, utilizando Ar como gas de purga y $\mathrm{N}_{2}$ como gas de trabajo, los productos de descomposición fueron propuestos de acuerdo a resultados de complexometría con EDTA y análisis elemental de los residuos. Se tomaron espectros UV-vis en el espectrofotómetro SHIMADZU UV-1700 PharmaSpec a temperatura ambiente en la región comprendida entre 200$400 \mathrm{~nm}$. Los diafractogramas de rayos X (DRX) en polvo fueron tomados en un rango $2 \Theta=5-60^{\circ}$ en un diafractómetro Panalytical X'Pert PRO utilizando una fuente de radicación de $\mathrm{Cu}$, con filtro de Ni y rendija de divergencia de $0.125^{\circ}$.

\section{Síntesis de los complejos lantánidos}

Se sintetizaron 7 complejos de Ln(III) empleando una reacción de metátesis entre el cloruro del lantánido $\mathrm{LnCl}_{3} \times \mathrm{xH}_{2} \mathrm{O}$ con la sal de sodio correspondiente, realizando una modificación al protocolo reportado en la literatura por Deacon y colaboradores [21]. Se describe detalladamente la síntesis del complejo 1. Los compuestos 2-7 fueron obtenidos empleando la misma ruta sintética (figura 1).

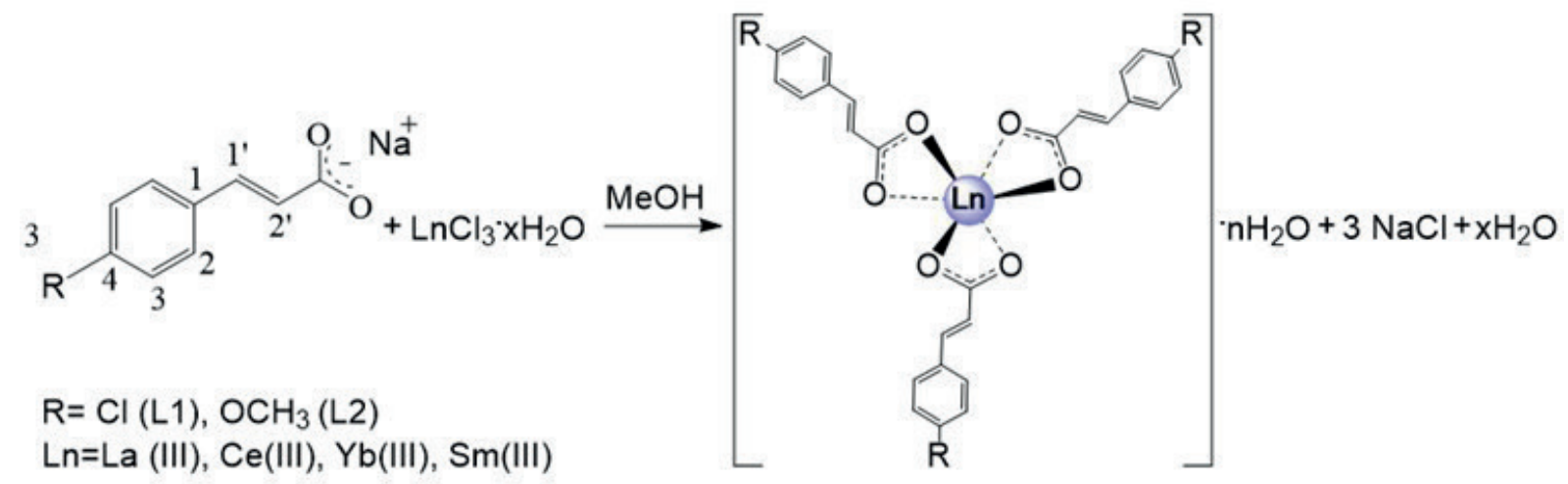

Figura 1. Esquema general propuesto para la síntesis de los complejos lantánidos con ligandos $p$-clorocinamato (L1) y $p$-metoxicinamato (L2). 
Síntesis de $\left[\mathrm{La}(4-\mathrm{Clcinn})_{3}\right] \cdot \mathbf{2} \cdot \mathbf{3} \mathrm{H}_{2} \mathrm{O}$ (1) Inicialmente se obtuvo el cinamato L1, [ $\mathrm{Na}(4-\mathrm{Cl}-$ Cinn)], para ello se disolvió $\mathrm{NaOH}(0.10 \mathrm{~g}, 2.50$ $\mathrm{mmol})$ en metanol $(5.0 \mathrm{~mL})$, luego se adicionó 4-ClCinn (399.6 mg, $2.18 \mathrm{mmol}$ ) y se mantuvo la solución en agitación por 10 minutos a temperatura ambiente. Al formarse un precipitado blanco, se adicionó $\mathrm{LaCl}_{3} \cdot 7 \mathrm{H}_{2} \mathrm{O}(271.4 \mathrm{mg}, 0.73 \mathrm{mmol})$ y $10.0 \mathrm{~mL}$ de metanol, se agitó por $3 \mathrm{~h}$ a temperatura ambiente, se filtró, se lavó con metanol y se secó a $100{ }^{\circ} \mathrm{C}$ por 24 horas. Porcentaje de rendimiento: (426.2 mg; 81.0\%), $\mathrm{C}_{27} \mathrm{H}_{22.6} \mathrm{Cl}_{3} \mathrm{LaO}_{8.3}$, Análisis elemental: C 45.34 (calc. 47.02), H 2.78 (2.73), La 19.80 (calc. 20.14). IR (ATR cm-1): 1635 s, 1506 m, 1489 s, 1409 vs, 1390 vs, 1280 w, 1246 m, 1089 s, 1012 m, 979 s, 821 vs, 738 m, 665 w. Raman (cm-1): $3066 \mathrm{~m}, 1639$ vs, 1590 vs, $1434 \mathrm{w}, 1291$ w, $1250 \mathrm{~m}, 1202 \mathrm{w}, 1176 \mathrm{w}, 1093 \mathrm{~m}, 747 \mathrm{w}, 725$ w, 632 w. RMN ${ }^{1} \mathrm{H}\left(\mathrm{DMSO}_{\mathrm{d}}\right) \delta(\mathrm{ppm}): 6.46(\mathrm{~d}$, $3 \mathrm{H},{ }^{3} \mathrm{~J}=16 \mathrm{~Hz}, \mathrm{H}-2$ '), 7.36 (d, 6H, $\left.{ }^{3} \mathrm{~J}=8 \mathrm{~Hz}, \mathrm{H}-2\right)$, 7.38 (d, 3H, $3 J=16 \mathrm{~Hz}, \mathrm{H}-1$ ') 7.55 (d, 6H, ${ }^{3} \mathrm{~J}=8$ Hz, H-3). RMN ${ }^{13} \mathrm{C}$ (DMSO-d ${ }_{6}$ ) $\delta$ (ppm): 126.6 (C-2'), 128.7 (C-3), 129.2 (C-2), 133.4 (C-1), 134.3 (C-4), $138.3\left(\mathrm{C}-1^{\prime}\right), 176.3(\mathrm{C}=\mathrm{O})$. DRX en polvo [espaciado-d/(0.1 nm) $\left(\mathrm{I} / \mathrm{I}^{\circ}\right)$ ]: 11.15(74), 7.38(100), 5.52(17), 5.41(5), 4.13(16), 4.00(6), 3.64(35), 2.73(5), 2.20(7), 2.00(5). TGA pérdida de masa: $0.85 \%\left(87-110{ }^{\circ} \mathrm{C}, 1\right.$ paso, calc. $\left.1 / 3 \times \mathrm{H}_{2} \mathrm{O}=0.87 \%\right)$, $5.14 \%\left(240-317^{\circ} \mathrm{C}\right.$, 1 paso, calc. $\left.2 \times \mathrm{H}_{2} \mathrm{O}=5.26 \%\right)$, $34.65 \%\left(317-553{ }^{\circ} \mathrm{C}, 3\right.$ pasos, calc. Producto $\left.0.9 \mathrm{La}_{2}\left(\mathrm{CO}_{3}\right)_{3}=36.46 \%\right)$.

Síntesis de $\left[\mathrm{Ce}(4-\mathrm{Clcinn})_{3}\right] \cdot 0.7 \mathrm{H}_{2} \mathrm{O}$ (2) Porcentaje de rendimiento: (391.9 mg; 76.5\%), $\mathrm{C}_{27} \mathrm{H}_{19.4} \mathrm{Cl}_{3} \mathrm{CeO}_{6.7}$, Análisis elemental: C 44.90 (calc. 46.49), 2.73 (calc. 2.80), Ce 20.31 (calc. 20.09). IR (ATR cm-1): $1635 \mathrm{~s}, 1506 \mathrm{~m}, 1489 \mathrm{~s}$, 1411 vs, 1388 vs, 1282 w, 1246 m, 1089 s, 1012 m, 979 s, 823 vs, 738 m, 667 w. Raman $\left(\mathrm{cm}^{-1}\right)$ : 3064 w, 1636 vs, 1588 vs, 1408 w, 1288 w, 1246 $\mathrm{m}, 1173 \mathrm{~m}, 1085 \mathrm{~m}, 748 \mathrm{w}, 627 \mathrm{w}$. TGA pérdida de masa: $0.88 \%\left(49-110{ }^{\circ} \mathrm{C}, 1\right.$ paso, calc. $\left.0.34 \times \mathrm{H}_{2} \mathrm{O}=0.88 \%\right), 0.92 \%\left(163-225{ }^{\circ} \mathrm{C}, 1\right.$ paso, calc. $\left.0.35 \times \mathrm{H}_{2} \mathrm{O}=0.91 \%\right), 34.80 \%\left(225-515{ }^{\circ} \mathrm{C}, 3\right.$ pasos, calc. Producto $\mathrm{Ce}_{2}\left(\mathrm{CO}_{3}\right)_{3}=32.15 \%$ ).

Síntesis de $\left[\mathbf{S m}(4-C l c i n n)_{3}\right] \cdot \mathrm{H}_{2} \mathrm{O}$ (3) Porcentaje de rendimiento: (450.8 mg; $86.6 \%$ ), $\mathrm{C}_{27} \mathrm{H}$ ${ }_{20} \mathrm{Cl}_{3} \mathrm{SmO}_{7}$, Análisis elemental: C 45.62 (calc.
45.47), H 2.79 (cal. 2.83), Sm 21.80 (calc. 22.49). IR (ATR cm-1): $1635 \mathrm{~s}, 1560 \mathrm{w}, 1517 \mathrm{~s}, 1490 \mathrm{~s}$, 1409 vs, 1384 vs, 1288 w, 1242 m, 1089 s, 1012 m, 981 s, 821 vs, 742 m, 667 w. Raman $\left(\mathrm{cm}^{-1}\right)$ : 3063 w, 1637 vs, 1588 vs, 1407 w, 1246 m, 1173 m, 1084 m, 755 w, $628 \mathrm{w}$.

Síntesis de [Yb(4-Clcinn) $)_{3}$ (4) Porcentaje de rendimiento: (383.6 mg; 73.2\%), $\mathrm{C}_{27} \mathrm{H}_{18} \mathrm{Cl}_{3} \mathrm{YbO}_{6}$, Análisis elemental: C 45.10 (calc. 45.18), H 2.43 (calc. 2.53), Yb 22.32 (calc. 22.44). IR (ATR cm1): 1639 s, $1595 \mathrm{~m}, 1558 \mathrm{w}, 1512 \mathrm{~m}, 1489 \mathrm{~s}, 1409$ vs, $1381 \mathrm{vs}, 1288 \mathrm{w}, 1246 \mathrm{~m}, 1087 \mathrm{~s}, 1012 \mathrm{w}, 975$ s, 815 vs, $761 \mathrm{~m}, 725 \mathrm{~m}, 657 \mathrm{~m}$. Raman $\left(\mathrm{cm}^{-1}\right)$ : 3040 vs, 2921 m, 1639 s, 1588 s, 1408 w, 1244 m, $1175 \mathrm{w}, 1083 \mathrm{w}, 968 \mathrm{vw}, 721 \mathrm{vw}, 625 \mathrm{vw}$.

Síntesis de $\left[\mathrm{Ce}(4-\mathrm{MeOcinn})_{3}\right] \cdot 0.2 \mathrm{H}_{2} \mathrm{O}$ (5) Porcentaje de rendimiento: (435 mg; 76.6\%), $\mathrm{C}_{30} \mathrm{H}_{27.4} \mathrm{CeO}_{9.2}$, Análisis elemental: C 51.45 (calc. 53.33), H 3.93 (calc. 4.09), Ce 22.82 (calc. 22.91). IR (ATR cm-1): $1631 \mathrm{~m}, 1604 \mathrm{~m}, 1506 \mathrm{~s}$, 1423 s, 1386 vs, 1292 w, 1240 vs, 1170 vs, 1026 m, 983 m, 829 s, 779 m, 719 m. Raman $\left(\mathrm{cm}^{-1}\right)$ : 3069 vw, 1631 vs, 1599 vs, 1419 w, 1239 m, 1167 m, 979 vw, 856 vw, 775 w, 631 vw, 549 vw. TGA pérdida de masa: $0.58 \%\left(50-90{ }^{\circ} \mathrm{C}, 1\right.$ paso, calc. $\left.2 / 9 \times \mathrm{H}_{2} \mathrm{O}=0.58 \%\right), 38.80 \%\left(279-595{ }^{\circ} \mathrm{C}, 3\right.$ pasos, calc. $0.9 \mathrm{Ce}_{2}\left(\mathrm{CO}_{3}\right)_{3}=38.32 \%$ ).

Síntesis de $\left[\mathrm{Sm}(4-\mathrm{MeOcinn})_{3}\right] \cdot \mathrm{H}_{2} \mathrm{O}$ (6) Porcentaje de rendimiento: (544.5 mg; 92.5\%), $\mathrm{C}_{30} \mathrm{H}_{29} \mathrm{SmO}_{10}$, Análisis elemental: C 50.52 (calc. 51.48), H 4.09 (calc. 4.18), Sm 20.48 (calc. 21.48). IR (ATR cm-1): $1631 \mathrm{~m}, 1604 \mathrm{~m}, 1508 \mathrm{~s}, 1425 \mathrm{~s}$, 1386 vs, 1303 w, 1240 vs, 1170 vs, 1024 m, 985 m, 831 s, 779 m, 723 m. Raman (cm-1): 3067 vw, 1633 vs, 1599 vs, 1435 w, 1243 s, 1167 s, 980 vw, $874 \mathrm{vw}, 776 \mathrm{w}, 631 \mathrm{vw}$.

Síntesis de $\left[\mathbf{Y b}(4-M e O c i n n)_{3}\right] \cdot 0.5 \mathrm{H}_{2} \mathrm{O}$ (7) Porcentaje de rendimiento: (598.3 mg; 99.0\%), $\mathrm{C}_{30} \mathrm{H}_{28} \mathrm{YbO}_{9.5}$, Análisis elemental: C 50.82 (calc. 50.49), H 3.74 (calc. 3.96), Yb 23.09 (calc. 23.67). IR (ATR cm-1): 1629 m, 1598 m, 1508 s, 1423 m, 1386 vs, 1307 w, 1238 vs, 1170 vs, 1022 m, 989 $\mathrm{m}, 825 \mathrm{~s}, 781 \mathrm{~m}, 723 \mathrm{~m}$. Raman ( $\left.\mathrm{cm}^{-1}\right): 3040 \mathrm{vs}$, $2384 \mathrm{~m}, 1625 \mathrm{~s}, 1602 \mathrm{~s}, 1422 \mathrm{w}, 1241 \mathrm{~s}, 1168 \mathrm{~s}$, $995 \mathrm{vw}, 773 \mathrm{vw}$. 


\section{Síntesis de los complejos de inclusión parcial y/o asociación.}

Se sintetizaron 7 complejos de inclusión mediante reacciones de co-precipitación, utilizando $\mathrm{N}, \mathrm{N}$ dimetilformamida (DMF) como solvente y una relación molar 1:3 (complejo lantánido: $\beta$-ciclodextrina). Se describe detalladamente la síntesis del complejo 8 (figura 2), los compuestos del 9-14 fueron obtenidos empleando la misma ruta sintética.

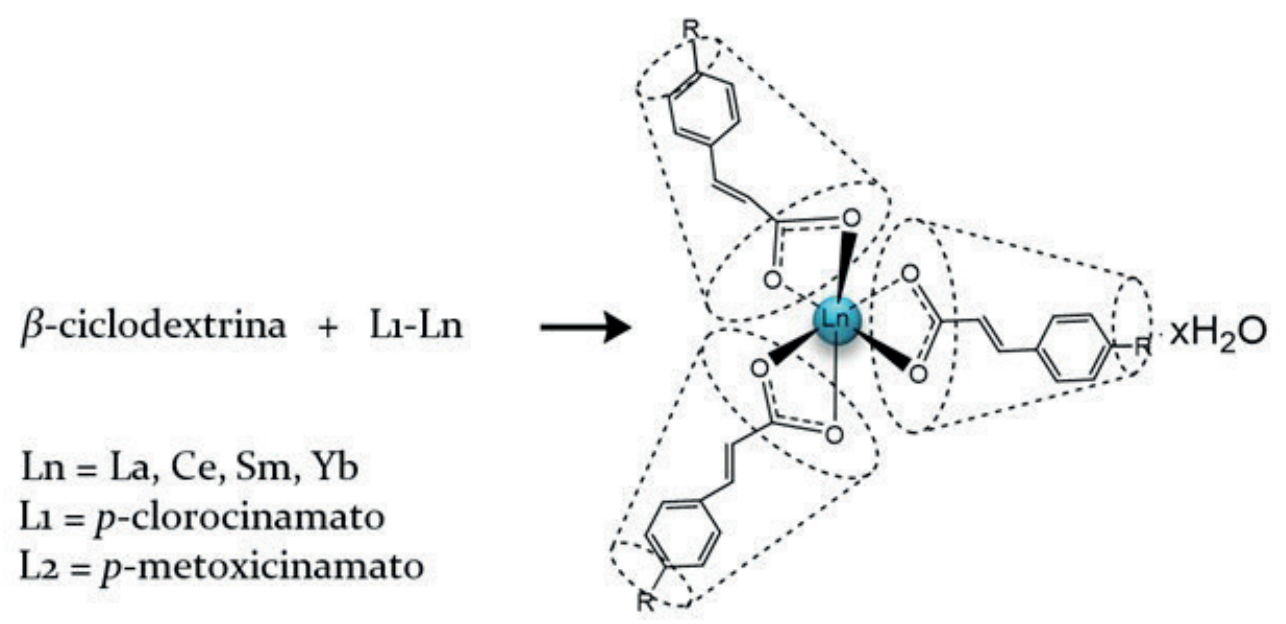

Figura 2. Esquema general de la síntesis de complejos de inclusión parcial y/o asociación. Tipo anfitrión - huésped ([Lx-Ln] $\beta-C D)$.

Síntesis del $\left[\mathrm{La}(4-\mathrm{Clcinn})_{3}\right] \cdot \boldsymbol{\beta}-\mathrm{CD} \cdot \mathbf{1 4 . 5} \mathrm{H}_{2} \mathrm{O}$ (8) Se disolvió (1) (30.4 mg, $0.04 \mathrm{mmol}$ ) en DMF $(2.0 \mathrm{~mL})$, luego se adicionó $\beta$-ciclodextrina (171.2 $\mathrm{mg}, 0.13 \mathrm{mmol}$ ), se mantuvo la solución en agitación por $3 \mathrm{~h}$ a temperatura ambiente. Se evaporó el solvente manteniendo la solución a $50{ }^{\circ} \mathrm{C}$ por $24 \mathrm{~h}$. Finalmente, se adicionó $20.0 \mathrm{~mL}$ de agua destilada, se agitó y se filtró, el sobrenadante se mantuvo por $48 \mathrm{~h}$ a $50{ }^{\circ} \mathrm{C}$ con el fin de eliminar el agua y obtener el complejo de inclusión. Porcentaje de rendimiento: (122.3 mg; 66,3\%), $\mathrm{C}_{153} \mathrm{H}_{285} \mathrm{Cl}_{3} \mathrm{LaO}_{139.5}$, Análisis elemental: C 40.15 (calc. 42.25), H 6.24 (calc. 5.96), La 2.83 (calc. 3.19). IR (ATR cm-1): $3331 \mathrm{~s}, 2924 \mathrm{vw}, 1639 \mathrm{~m}$, $1504 \mathrm{~m}, 1490 \mathrm{~m}, 1417 \mathrm{~m}, 1388 \mathrm{~m}, 1249 \mathrm{vw}, 1153$ m, 1078 m, 1024 vs, 997 vs, 937 m, 860 w, 825 w, 754 w, 704 w. Raman $\left(\mathrm{cm}^{-1}\right)$ : 2935 vs, 2904 vs, 1637 m, 1588 m, 1454 m, 1385 m, 1333 m, 1246 m, 1205 m, 1105 m, 1044 w, 941 m, 855 m, 749 w, $701 \mathrm{w}, 572 \mathrm{w}, 477 \mathrm{vs}, 436 \mathrm{~m}, 348 \mathrm{w}$. RMN ${ }^{1} \mathrm{H}$ $\left(\mathrm{DMSO}-\mathrm{d}_{6}\right) \delta$ (ppm): 6.43 (d, $\left.3 \mathrm{H}, 3 \mathrm{~J}=16 \mathrm{~Hz}, \mathrm{H}-2^{\prime}\right)$, 7.34 (d, $3 \mathrm{H}, 3 J=16 \mathrm{~Hz}, \mathrm{H}-1$ '), 7.42 (d, $6 \mathrm{H}, 3 \mathrm{~J}=8 \mathrm{~Hz}$, $\mathrm{H}-2), 7.61(\mathrm{~d}, 6 \mathrm{H}, 3 \mathrm{~J}=8 \mathrm{~Hz}, \mathrm{H}-3), 4.83\left(\mathrm{~d}, 7 \mathrm{H},{ }^{3} \mathrm{~J}=4\right.$ $\mathrm{Hz}, \mathrm{H}-\mathrm{a}), 3.30$ (m, 7H, H-b), 3.66-3.62 (m, 7H, $\mathrm{H}-\mathrm{c}), 3.37$ (m, 7H, H-d), 3.58-3.55 (m, 7H, H-e), 3.66-3.62 (m, 14H, H-f), 4.44 (t, 7H, $3 \mathrm{~J}=4 \mathrm{~Hz}$,
OH-f), 5.72 (s, 7H, $\left.{ }^{3} \mathrm{~J}=4 \mathrm{~Hz}, \mathrm{OH}-\mathrm{b}\right), 5.77$ (d, 7H, $\left.{ }^{3} J=4 \mathrm{~Hz}, \mathrm{OH}-\mathrm{c}\right) . \mathrm{RMN}{ }^{13} \mathrm{C}\left(\mathrm{DMSO}^{-\mathrm{d}_{6}}\right) \delta(\mathrm{ppm})$ : 127.5 (C-2'), 130.5 (C-3), 130.9 (C-2), 134.4 (C-1), 135.2 (C-4), $140.0(\mathrm{C}-1$ '), $178.58(\mathrm{C}=\mathrm{O}), 102.44$ (C-a), 72.54 (C-b), 73.55 (C-c), 82.04 (C-d), 72.91 (C-e), 60.42 (C-f). DRX en polvo [espaciado-d/ $\left.(0.1 \mathrm{~nm})\left(\mathrm{I} / \mathrm{I}^{\circ}\right)\right]$ : 14.24(27), 10.93(9), 9.89(11), 9.13(8), 8.34(34), 7.60(8), 7.11(60), 7.01(100), 6.03(6), 5.76(18), 5.52(10), 5.18(17), 5.03(20), $4.96(12), \quad 4.82(7), \quad 4.66(5), \quad 4.56(22), 4.51(23)$, 4.29(16), 4.12(7), 3.87(7), 3.74(7), 3.66(5), 3.55(6), 3.28(8). TGA pérdida de masa: $6.08 \%\left(80-133{ }^{\circ} \mathrm{C}\right.$, 1 paso, calc. $\left.14.5 \times \mathrm{H}_{2} \mathrm{O}=5.99 \%\right), 60.85 \%(248-353$ ${ }^{\circ} \mathrm{C}, 1$ paso, calc. Producto $6 \times$ glucopiranosa + $\left.\mathrm{La}_{2}\left(\mathrm{CO}_{3}\right)_{3}=62.43 \%\right)$.

Síntesis de $\left[\mathrm{Ce}(4-\mathrm{Clcinn})_{3}\right] \cdot \boldsymbol{\beta}-\mathrm{CD} \cdot \mathbf{7} \mathrm{H}_{2} \mathrm{O}$ (9) Porcentaje de rendimiento: (129.0 mg; 76.5\%), $\mathrm{C}_{153} \mathrm{H}_{242} \mathrm{Cl}_{3} \mathrm{CeO}_{118}$, Análisis elemental: C 39.97 (calc. 43.59), H 6.56 (calc. 5.79), Ce 3.00 (calc. 3.32). IR (ATR cm-1): $3319 \mathrm{~s}, 2926 \mathrm{vw}, 2358 \mathrm{vw}$, $2324 \mathrm{vw}, 1660 \mathrm{~m}, 1411 \mathrm{~m}, 1153 \mathrm{~m}, 1078 \mathrm{~m}, 1022$ vs, 997 vs, 937 m, 860 w, 754 w, 704 w. Raman (cm-1): 2904 vs, $1636 \mathrm{~m}, 1588 \mathrm{~m}, 1447 \mathrm{w}, 1381 \mathrm{~m}$, $1332 \mathrm{~m}, 1246 \mathrm{~m}, 1201 \mathrm{vw}, 1123 \mathrm{~m}, 1082 \mathrm{~m}, 1043$ m, $941 \mathrm{~m}, 848 \mathrm{~m}, 746 \mathrm{vw}, 701 \mathrm{vw}, 576 \mathrm{w}, 473$ 
s, $434 \mathrm{~m}, 348 \mathrm{w}, 316 \mathrm{vw}$. TGA pérdida de masa: $3.00 \%\left(81-132{ }^{\circ} \mathrm{C}, 1\right.$ paso, calc. $\left.7 \times \mathrm{H}_{2} \mathrm{O}=2,98 \%\right)$, $76.59 \%$ (194-389 ${ }^{\circ} \mathrm{C}, 2$ pasos, calc. Producto $3 \times$ glucopiranosa $\left.+\mathrm{Ce}_{2}\left(\mathrm{CO}_{3}\right)_{3}=75.53 \%\right)$.

Síntesis de $\left[\mathrm{Sm}(4-\mathrm{Clcinn})_{3}\right] \cdot \boldsymbol{\beta}-\mathrm{CD} \cdot \mathbf{1 8 \mathrm { H } _ { 2 } \mathrm { O }}$ (10) Porcentaje de rendimiento: $(150.1 \mathrm{mg}$; 84.5\%), $\mathrm{C}_{154} \mathrm{H}_{268} \mathrm{Cl}_{3} \mathrm{SmO}_{129}$, Análisis elemental: C 38.94 (calc. 41.66), H 6.42 (cal. 6.08), Sm 3.05 (calc. 3.39). IR (ATR cm-1): $3313 \mathrm{~s}, 2926 \mathrm{w}, 2358$ w, 2339 w, 1660 m, 1411 m, 1153 s, 1078 s, 1022 vs, 997 vs, 937 m, 862 w, 756 w, 704 w. Raman (cm-1): 2903 vs, $1635 \mathrm{~m}, 1588 \mathrm{~m}, 1454 \mathrm{w}, 1385 \mathrm{~m}$, 1333 m, 1245 w, 1125 m, 1042 w, 942 w, 848 w, $749 \mathrm{vw}, 702 \mathrm{vw}, 571 \mathrm{w}, 474 \mathrm{~s}, 435 \mathrm{~m}, 345 \mathrm{w}$. TGA pérdida de masa: $7.30 \%\left(67-137^{\circ} \mathrm{C}, 1\right.$ paso, calc. $\left.18 \times \mathrm{H}_{2} \mathrm{O}=7.32 \%\right), 56.88 \%\left(228-396{ }^{\circ} \mathrm{C}, 1\right.$ paso, calc. Producto $7 \times$ glucopiranosa $+\mathrm{Sm}_{2}\left(\mathrm{CO}_{3}\right)_{3}=$ $57.53 \%)$.

Síntesis de $\left[\mathbf{Y b}(4-C l c i n n)_{3}\right] \cdot \boldsymbol{\beta}-\mathbf{C D} \cdot \mathbf{2 3} \mathrm{H}_{2} \mathrm{O}$ (11) Porcentaje de rendimiento: (163.7 mg; 89.9\%), $\mathrm{C}_{154} \mathrm{H}_{278} \mathrm{Cl}_{3} \mathrm{YbO}_{134}$, Análisis elemental: C 39.49 (calc. 40.62), H 6.39 (calc. 6.15), Yb 2.87 (calc. 3.80). IR (ATR cm-1): $3317 \mathrm{~s}, 2924 \mathrm{w}, 2358$ w, $2341 \mathrm{w}, 1660 \mathrm{~m}, 1411 \mathrm{~m}, 1153 \mathrm{~s}, 1078 \mathrm{~s}, 1022$ vs, 999 vs, 937 m, 862 w, 756 w, 704 m. Raman (cm-1): 2903 vs, 2589 w, 1635 m, 1588 m, 1446 w, $1382 \mathrm{~m}, 1332 \mathrm{~m}, 1242 \mathrm{~m}, 1123 \mathrm{~m}, 1039$ w, 942 m, $848 \mathrm{~m}, 749 \mathrm{vw}, 703 \mathrm{vw}, 569 \mathrm{~m}, 473 \mathrm{vs}, 435 \mathrm{~m}$, 351 w. TGA pérdida de masa: $8.88 \%\left(39-147^{\circ} \mathrm{C}\right.$, 1 paso, calc. $\left.23 \times \mathrm{H}_{2} \mathrm{O}=9.12 \%\right), 62.60 \%$ (231-394 ${ }^{\circ} \mathrm{C}, 1$ paso, calc. Producto $6 \times$ glucopiranosa + $\left.\mathrm{Yb}_{2}\left(\mathrm{CO}_{3}\right)_{3}=61.03 \%\right)$.

Síntesis de $\left[\mathrm{Ce}(4-\mathrm{MeOcinn})_{3}\right] \cdot \beta-\mathrm{CD} \cdot \mathbf{2 1 \mathrm { H } _ { 2 } \mathrm { O }}$ (12) Porcentaje de rendimiento: (157.4 mg; 86.0\%), $\mathrm{C}_{157} \mathrm{H}_{283} \mathrm{CeO}_{135}$, Análisis elemental: $\mathrm{C}$ 40.53 (calc. 42.18), H 6.63 (calc. 6.38), Ce 2.60 (calc. 3.13). IR (ATR cm-1): 3309 s, 2924 w, 2358 m, $2341 \mathrm{~m}, 1658 \mathrm{~m}, 1512 \mathrm{~m}, 1423 \mathrm{~m}, 1244 \mathrm{~m}$, $1153 \mathrm{~s}, 1078 \mathrm{~s}, 1022$ vs, 999 vs, 937 m, 862 w, 754 w, 704 m. Raman (cm-1): 2905 vs, 1635 vs, 1601 vs, 1447 w, 1382 m, 1332 m, 1242 s, 1167 m, 1122 m, 1079 m, 1040 m, 941 m, 857 m, 773 vw, 703 vw, $633 \mathrm{vw}, 573 \mathrm{w}, 473 \mathrm{~s}, 434 \mathrm{~m}, 353 \mathrm{w}$. TGA pérdida de masa: $8.40 \%\left(45-126^{\circ} \mathrm{C}, 1\right.$ paso, calc. $\left.21 \times \mathrm{H}_{2} \mathrm{O}=8.48 \%\right), 62.95 \%\left(246-396{ }^{\circ} \mathrm{C}, 1\right.$ paso, calc. Producto $6 \times$ glucopiranosa $+\mathrm{Ce}_{2}\left(\mathrm{CO}_{3}\right)_{3}=$ $62.20 \%)$.
Síntesis de $\left[\mathrm{Sm}(4-\mathrm{MeOcinn})_{3}\right] \cdot \boldsymbol{\beta}-\mathrm{CD} \cdot \mathbf{1 7} \mathrm{H}_{\mathbf{2}} \mathrm{O}$ (13) Porcentaje de rendimiento: (140.7 mg; 81.1\%), $\mathrm{C}_{156} \mathrm{H}_{271} \mathrm{SmO}_{121}$, Análisis elemental: C 39.72 (calc. 42.65), H 6.56 (calc. 6.22), Sm 2.78 (calc. 3.42). IR (ATR cm-1): 3313 s, $2922 \mathrm{w}, 2358 \mathrm{~m}$, $2341 \mathrm{~m}, 1658 \mathrm{~m}, 1512 \mathrm{~m}, 1409 \mathrm{~m}, 1242 \mathrm{~m}, 1153$ s, 1078 s, 1022 vs, 997 vs, 945 m, 862 w, 829w, 754 w, 704 m. Raman (cm-1): 2938 vs, 2903 vs, 1633 vs, 1600 vs, 1447 m, 1418 m, 1330 m, 1243 s, $1167 \mathrm{~s}, 1128 \mathrm{~m}, 1041 \mathrm{~m}, 941 \mathrm{~m}, 856 \mathrm{~m}, 775 \mathrm{w}$, $701 \mathrm{vw}, 633 \mathrm{vw}, 570 \mathrm{w}, 473 \mathrm{~s}, 435 \mathrm{w}, 351 \mathrm{w}$. TGA pérdida de masa: $7.01 \%\left(81-134{ }^{\circ} \mathrm{C}, 1\right.$ paso, calc. $\left.17 \times \mathrm{H}_{2} \mathrm{O}=6.96 \%\right), 67.47 \%\left(247-384{ }^{\circ} \mathrm{C}, 1\right.$ paso, calc. Producto $5 \times$ glucopiranosa $+\mathrm{Sm}_{2}\left(\mathrm{CO}_{3}\right)_{3}=$ $66.20 \%)$.

\section{Síntesis de $\left[\mathrm{Yb}(4-\mathrm{MeOcinn})_{3}\right] \cdot \boldsymbol{\beta}-\mathrm{CD} \cdot \mathbf{2} 1 \mathrm{H}_{2} \mathrm{O}$} (14) Porcentaje de rendimiento: (150.3 mg; 81.8\%), $\mathrm{C}_{156} \mathrm{H}_{279} \mathrm{YbO}_{135}$, Análisis elemental: $\mathrm{C}$ 39.00 (calc. 41.75), H 6.55 (calc. 6.27), Yb 2.71 (calc. 3.86). IR (ATR cm-1): $3311 \mathrm{~s}, 2922 \mathrm{w}, 1658$ m, $1641 \mathrm{~m}, 1604 \mathrm{w}, 1512 \mathrm{w}, 1423 \mathrm{~m}, 1247 \mathrm{~m}, 1153$ s, 1101 vw, 1078 s, 1022 vs, 997 vs, 937 m, 862 w, 829 w, 754 w, 702 m, 646 m. Raman (cm-1): 2939 vs, 2905 vs, 1635 vs, 1600 vs, $1447 \mathrm{w}, 1382 \mathrm{~m}$, $1332 \mathrm{~m}, 1242 \mathrm{~s}, 1167 \mathrm{~m}, 1122 \mathrm{~m}, 1040 \mathrm{~m}, 941 \mathrm{~m}$, 857 m, 773 w, 703 vw, 633 vw, 573 w, 473 s, 434 $\mathrm{m}, 347 \mathrm{w}$. TGA pérdida de masa: $8.42 \%(84-136$ ${ }^{\circ} \mathrm{C}, 1$ paso, calc. $21 \times \mathrm{H}_{2} \mathrm{O}=8.42 \%$ ), $65.68 \%$ (254$356{ }^{\circ} \mathrm{C}, 1$ paso, calc. Producto $5 \times$ glucopiranosa $\left.+\mathrm{Yb}_{2}\left(\mathrm{CO}_{3}\right)_{3}=65.29 \%\right)$.

\section{Ensayos de actividad antibacteriana}

Se determinó la actividad antibacteriana en dos cepas gram-positivas ( $S$. aureus ATCC 25923 y $S$. aureus ATCC 29213), y cuatro cepas gram-negativas (E. coli ATCC 25922, P. aeruginosa ATCC 27853, S. Typhimurium ATCC 14028 y K. pneumoniae ATCC BAA-2146), utilizando el método M31-A3, recomendado por el CLSI (Clinical and Laboratory Standards Institute) [22]. La concentración mínima inhibitoria (CMI), se determinó a diferentes concentraciones $(4000$ hasta $7.8 \mu \mathrm{g} / \mathrm{mL}$ ). Se preparó una solución de compuesto puro en DMSO $(50 \mathrm{mg} / \mathrm{mL})$, a partir de esta solución madre se realizaron diluciones con caldo Mueller-Hinton en una placa de 96 pocillos. El inóculo se adicionó en caldo Mueller-Hinton y la suspensión se ajustó aproximada- 
mente a 1 x $10^{6} \mathrm{UFC} / \mathrm{mL}$. Como control negativo se empleó caldo Mueller-Hinton sin bacterias ni compuestos, como control positivo se empleó caldo Mueller-Hinton con bacteria. Al terminar la preparación de las placas se incubaron a $37^{\circ} \mathrm{C}$ por 24 horas.

\section{Pruebas de interacción con ADN}

Para evaluar la posible interacción de los compuestos obtenidos con la molécula de ADN, se utilizaron las técnicas UV-vis y electroforesis. En la primera de ellas se realizaron dos ensayos utilizando Fibras tipo I D1501 de ADN de Timo de ternera liofilizado, de la marca Sigma Aldrich. Para el método por electroforesis se empleó ADN E. coli pBR322 D9893, de la marca Sigma Aldrich. Para los ensayos por UV-vis se utilizó un equipo Jasco V-730 con control de temperatura a $20^{\circ} \mathrm{C}$. Se evaluaron concentraciones entre 5-15 $\mu \mathrm{M}$ de complejo lantánido y $10-50 \mu \mathrm{M}$ complejo de inclusión, manteniendo constante la concentración de ADN de Timo de ternera en fibras tipo I (153 $\mu \mathrm{M}$ nucleótidos). En otro ensayo se evaluaron concentraciones de ADN entre 10-50 $\mu \mathrm{M}$ nucleótidos, manteniendo constante las concentraciones de complejo lantánido $(20 \mu \mathrm{M})$ y de inclusión $(70 \mu \mathrm{M})$. Para la preparación de estas soluciones se utilizó un buffer de Tris- $\mathrm{HCl}$ $(50 \mathrm{mM})$ con $\mathrm{NaCl}(5 \mathrm{mM})$ y EDTA $(25 \mathrm{mM})$ a pH 7.2 y una solución de ADN Stock (2.5mg en $3.0 \mathrm{~mL}$ de Buffer Tris-HCl/NaCl/EDTA $50 \mathrm{mM} / 5$ $\mathrm{mM} / 25 \mathrm{mM}$ ) con relación A260/A280 igual a 1.8.

Para el segundo método se utilizó una cámara electroforética Thermo Scientific EasyCast TM B2 Mini y un transiluminador de luz visible UVP VB-26V. Las muestras se prepararon utilizando concentraciones de 10,30 y $50 \mu \mathrm{M}$ de complejo lantánido e inclusión, en buffer de Tris-HCl (50 $\mathrm{mM})$ con $\mathrm{NaCl}(5 \mathrm{mM})$ y EDTA $(25 \mathrm{mM})$ a $\mathrm{pH}$ 7.2 y TAE $1 \mathrm{X}$ (Tris- $\left.\mathrm{HCl} / \mathrm{CH}_{3} \mathrm{COOH} / \mathrm{EDTA}\right)$ a $\mathrm{pH}$ 8.3, se adicionó $4.5 \mu \mathrm{L}$ de ADN E. coli pBR322 D9893 Sigma Aldrich (100 ng/ $\mu \mathrm{L})$, y de forma intercalada $1.3 \mu \mathrm{L}$ de $\mathrm{H}_{2} \mathrm{O}_{2}(5.0 \mathrm{mM})$. Las muestras se incubaron por dos horas a $37^{\circ} \mathrm{C}$ y
900 rpm. Luego de la incubación se adicionó a cada muestra el tampón de carga (bromofenol y glicerol) y se inyectaron en el gel de agarosa $1 \%$ previamente teñida con gel Green 1X; se utilizó como marcador HyperLadder III Bioline. La corrida se llevó a cabo durante 75 minutos a 100 V y $130 \mathrm{~mA}$.

\section{RESULTADOS Y DISCUSIÓN}

\section{Síntesis y caracterización de los complejos lantánidos.}

Los complejos lantánidos fueron sintetizados a partir de una reacción de metátesis entre el cloruro del lantánido $\mathrm{LnCl}_{3} \cdot \mathrm{xH}_{2} \mathrm{O}$ y el ligando cinamato correspondiente, obteniendo porcentajes de rendimiento entre $73-99 \%$. Los porcentajes experimentales de $\mathrm{H}$ y $\mathrm{C}$ con respecto a los valores calculados, así como los porcentajes de metal obtenidos a partir de complexometría con EDTA, permiten sugerir las estructuras propuestas que fueron apoyadas con las diferentes técnicas de caracterización. En la caracterización de los complejos lantánidos 1-7 por espectroscopía de FT-IR (ver figuras 3a, Información suplementaria 1S-6S), se observan las bandas de vibración características de los ligandos cinamato, las bandas en la región entre $1640-1620 \mathrm{~cm}^{-1}$ corresponden a la vibración de tensión del enlace $\mathrm{C}=\mathrm{C}$ de la cadena alifática, las bandas de vibración de tensión asimétrica y simétrica del $\mathrm{CO}_{2}$ entre 1520 - 1500 $\mathrm{cm}^{-1}$ y $1430-1400 \mathrm{~cm}^{-1}$, respectivamente. Estas bandas presentan desplazamiento batocrómico respecto a las bandas de los cinamatos cuyo $\Delta \boldsymbol{v}$ confirma la participación del carboxilo en la coordinación con los iones lantánidos, actuando como agentes quelantes bidentados (ver tabla 1 y figura 3a) [23]. En los espectros IR se observa la banda de vibración de deformación del enlace $=C-H$ alifático fuera del plano entre $990-970$ $\mathrm{cm}^{-1}$, indicando que el enlace $\alpha, \beta$-insaturado se conserva en posición trans, mientras que la banda de estiramiento del enlace $L n$ - 0 se observa a $730-780 \mathrm{~cm}^{-1}$, de baja intensidad debido al predominante carácter electrostático [24]. 
Tabla 1. Principales bandas en FT-IR para los ligandos $\mathrm{Na}$ (4-Clcinn), $\mathrm{Na}$ (4-MeOcinn) y sus respectivos complejos con La, Ce, Sm e Yb.

\begin{tabular}{lccccccc}
\hline \multicolumn{1}{c}{ Comp. } & $\boldsymbol{v}(\boldsymbol{C}=\boldsymbol{C})$ & $\boldsymbol{v}_{\boldsymbol{a s}}\left(\boldsymbol{C O}_{\mathbf{2}}\right)$ & $\boldsymbol{v}_{\boldsymbol{s}}\left(\boldsymbol{C} \boldsymbol{O}_{\mathbf{2}}\right)$ & $\boldsymbol{\Delta} \boldsymbol{v}$ & $\boldsymbol{\delta}(=\boldsymbol{C H})$ & $\boldsymbol{\delta}(\boldsymbol{C}-\boldsymbol{H})_{\boldsymbol{o p}}$ & $\boldsymbol{v}(\boldsymbol{L n}-\boldsymbol{O})$ \\
\hline L1 & $\mathbf{1 6 4 3}$ & $\mathbf{1 5 4 1}$ & $\mathbf{1 4 2 3}$ & $\mathbf{1 4 1}$ & $\mathbf{9 6 8}$ & $\mathbf{8 2 9}$ & - \\
LaL1 & 1635 & 1506 & 1409 & 97 & 979 & 821 & 736 \\
CeL1 & 1635 & 1506 & 1411 & 95 & 979 & 823 & 738 \\
SmL1 & 1635 & 1517 & 1409 & 108 & 981 & 821 & 754 \\
YbL1 & 1639 & 1512 & 1409 & 103 & 975 & 815 & 761 \\
L2 & $\mathbf{1 6 3 9}$ & $\mathbf{1 5 4 8}$ & $\mathbf{1 4 2 7}$ & $\mathbf{1 4 0}$ & $\mathbf{9 6 6}$ & $\mathbf{8 2 7}$ & - \\
CeL2 & 1631 & 1506 & 1423 & 83 & 983 & 829 & 779 \\
SmL2 & 1631 & 1508 & 1425 & 83 & 985 & 831 & 779 \\
YbL2 & 1629 & 1508 & 1423 & 85 & 989 & 825 & 781 \\
\hline
\end{tabular}

L1 = Na(4-Clcinn), L2 = Na(4-MeOcinn)

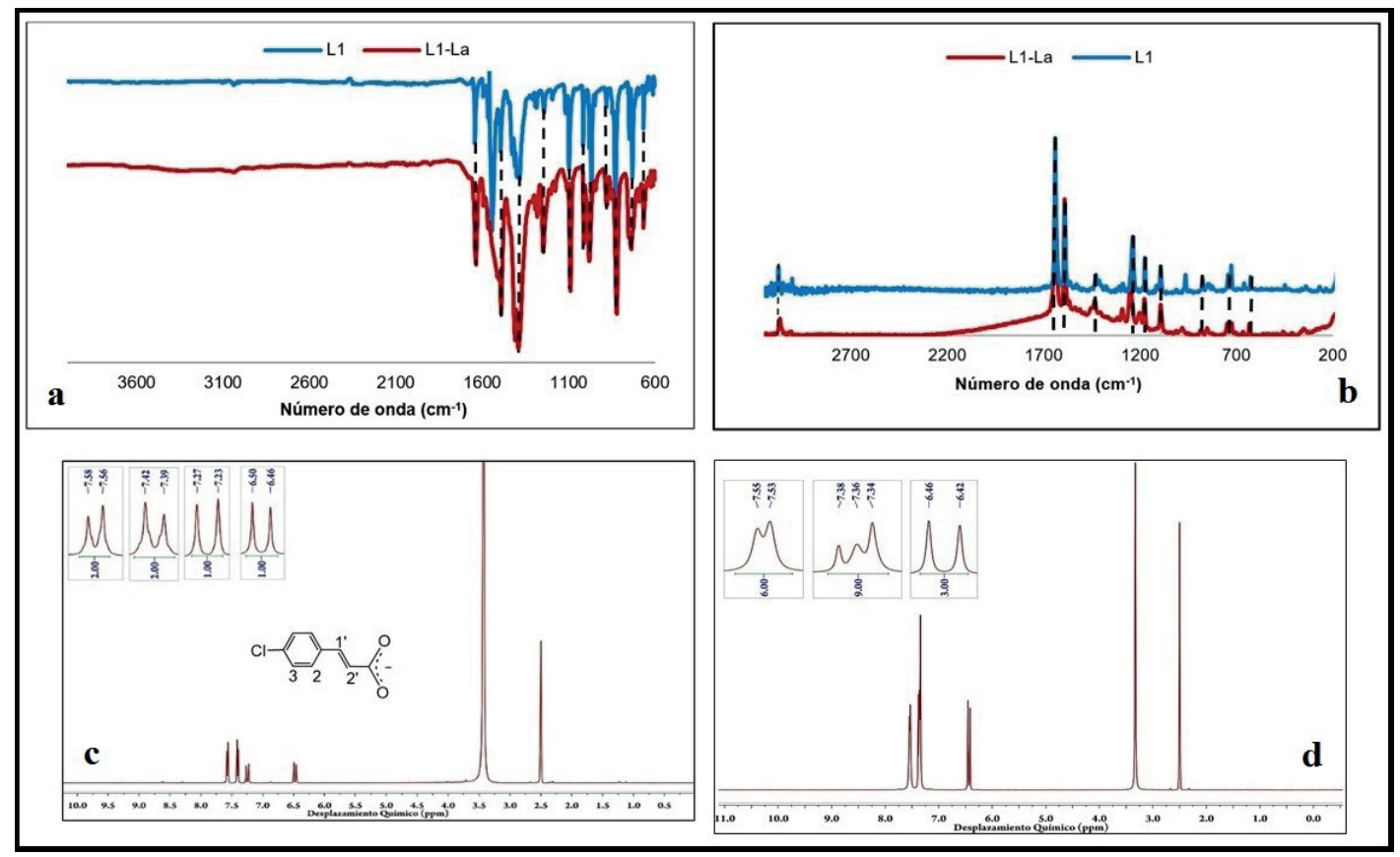

Figura 3. a) Espectro IR comparativo entre L1 y L1-La. b) Espectro Raman comparativo entre L1 y L1-La.

c) Espectro RMN ${ }^{1} \mathrm{H}$ de L1. d) Espectro RMN ${ }^{1} \mathrm{H}$ de L1-La

En la caracterización de los compuestos 1-7 por espectroscopía Raman, se observan bandas de vibración similares a las reportadas en el infrarrojo ya que implican los mismos modos vibraciónales, sin embargo, se observan corrimientos o cambios en la intensidad de las bandas, consecuencia de la dispersión causada por polarizabilidad de los enlaces presentes.

En las figuras 3b y 13S-18S (información suplementaria), se observan las bandas correspondientes a la vibración de tensión asimétrica del enlace C-H aromático entre $3060-3040 \mathrm{~cm}^{-1}$, las bandas de vibración de tensión del enlace $\mathrm{C}=\mathrm{C}$ de la cadena alifática entre $1640-1620$ $\mathrm{cm}^{-1}$, las bandas de vibración de tensión asimétrica y simétrica del $\mathrm{CO}_{2}$ entre $1600-1580 \mathrm{~cm}^{-1}$ y $1430-1400 \mathrm{~cm}^{-1}$, que presentan diferencias en la intensidad con respecto a las bandas del infrarrojo siendo la asimétrica más intensa que la simétrica (ver figura 3b), lo cual se explica por la polarizabilidad del enlace carboxilo. También se logra identificar la banda de estiramiento del enlace $L n$ - 0 entre $620-640 \mathrm{~cm}^{-1}$. En el espectro RMN ${ }^{1} \mathrm{H}$ del $\mathrm{Na}(4-\mathrm{Clcinn}$ ) (figura $3 \mathrm{c}$ ) se observan cuatro señales, un doblete en $6.50 \mathrm{ppm}$ asignado al protón 2' desplazado a campo alto por el efecto inductivo del grupo carboxilo, un doblete a 7.27 ppm asignado al protón 1' donde $3 J$ entre 1' y 2' es $16 \mathrm{~Hz}$, lo cual indica que los hidrógenos están 
dispuestos en posición trans, también se observan los dobletes asignados al protón $\mathbf{2}$ en 7.42 ppm y al protón 3 en 7.58 ppm, este último desplazado a campo bajo porque el cloro actúa como grupo electroatractor, ${ }^{3} J$ entre 2 y $\mathbf{3}$ es igual $8 \mathrm{~Hz}$ indicando que son protones vecinos.

En el espectro RMN ${ }^{1} \mathrm{H}$ del complejo L1-La (figura 3d) se observan las mismas señales obtenidas para el espectro del ligando $\mathrm{Na}$ (4-Clcinn) (figura 3c), conservando las mismas constantes de acoplamiento, pero se desplazan a campo alto por el efecto protector ocasionado por la deslocalización de los electrones del carboxilo al coordinarse al metal.

De acuerdo al estudio vibraciónal y la caracterización espectroscópica se propone que toda la serie de complejos lantánidos sintetizados presentan coordinación bidentada a través de los oxígenos carboxílicos del cinamato y los iones lantánidos.

\section{Síntesis y caracterización de los complejos de inclusión parcial.}

Para la síntesis de los complejos de inclusión parcial se empleó la reacción de co-precipitación entre la $\beta$-CD y los complejos lantánidos utilizan- do N,N dimetilformamida (DMF) como solvente. Se obtuvieron porcentajes de rendimientos entre $66-90 \%$.

Se realizó el estudio vibraciónal por FT-IR y Raman para observar el desplazamiento o desaparición de las bandas de la molécula huésped. En el FT-IR comparativo de la Figura 4a se puede observar la aparición de nuevas bandas que corresponden a la $\beta-\mathrm{CD}$, algunas de ellas son la banda de vibración de tensión del enlace $O-H$ entre $3330-3300 \mathrm{~cm}^{-1}$, la banda de vibración de deformación en el plano del enlace $O-H$ entre $1160-1150 \mathrm{~cm}^{-1}$, la banda de vibración de tensión del enlace $C$ - $O$ entre $1030-1020 \mathrm{~cm}^{-1}$ y la banda de vibración de deformación fuera del plano del enlace $O-H$ en $704 \mathrm{~cm}^{-1}$, las señales coinciden a lo reportado en la literatura [25].

Además, se observa en los complejos de inclusión el desplazamiento de las bandas correspondientes a la $\beta-\mathrm{CD}$ a menor frecuencia (ver figura 4a, información suplementaria 7S-12S), la disminución de la intensidad de las bandas correspondientes a los enlaces $\mathrm{C}=\mathrm{C}$ y $\mathrm{CO}_{2}$, lo cual infiere la formación del enlace de hidrógeno que modifica las vibraciónes de la molécula y disminuye la interacción de la misma con la radiación electromagnética del FT-IR.

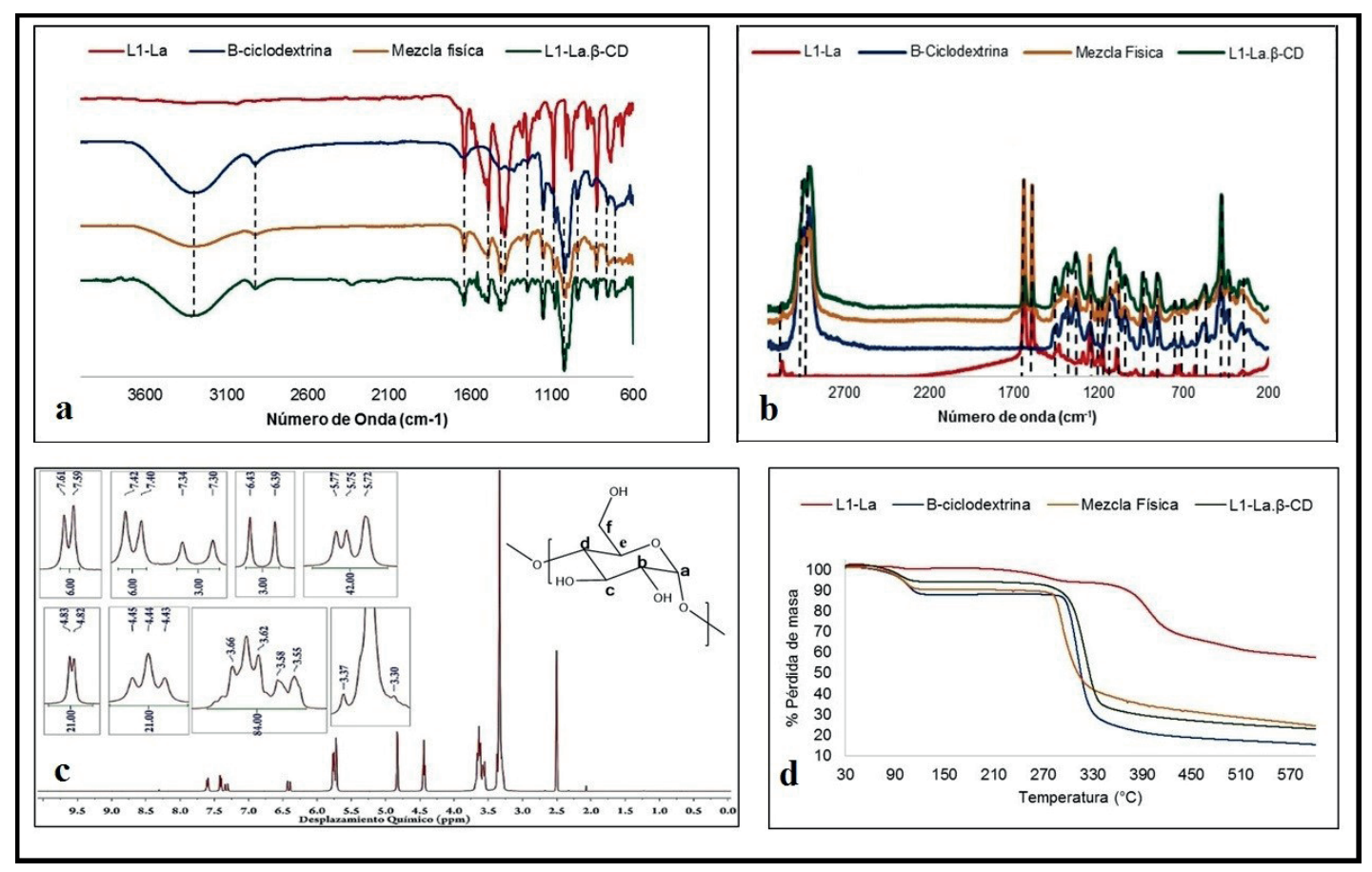

Figura 4. a) Espectro FT-IR comparativo (entre L1-La, $\beta-\mathrm{CD}$, Mezcla física (L1-La/ $\beta-\mathrm{CD}$ ) y L1-La· $\beta$ CD). b) Espectro Raman comparativo c) Espectro RMN ${ }^{1} \mathrm{H}$ de L1-La· $\beta-\mathrm{CD}$ d) TGA comparativo. 
En la figura $4 \mathrm{~b}$ se observan los espectros Raman superpuestos de la $\beta-C D$, la mezcla física (L1-La/ $\beta-C D)$ y el complejo de inclusión. Se identifican las mismas bandas de vibración que se observan en los espectros de la figura $4 a$, además de bandas observadas por la presencia de la $\beta-C D$, como las de vibración de tensión de enlace $C-H$ asimétrica y simétrica entre 2940 $2930 \mathrm{~cm}^{-1}$ y $2910-2900 \mathrm{~cm}^{-1}$, respectivamente. Igualmente, se asignan las bandas de vibración de deformación fuera del plano del anillo de la glucopiranosa entre $580-570 \mathrm{~cm}^{-1}$ y $480-470$ $\mathrm{cm}^{-1}$. Se conservan con menor intensidad algunas bandas del ligando como la banda de vibración de tensión del enlace $C=C$ de la cadena alifática, las bandas de vibración de tensión asimétrica y simétrica del $\mathrm{CO}_{2}$ y la banda de vibración de deformación del enlace $C$ - $H$ aromático en el plano, sin embargo, se nota la desaparición del resto de bandas incluyendo la banda correspondiente a la vibración de tensión asimétrica del $\mathrm{CO}_{2}$.

En el espectro RMN ${ }^{1} \mathrm{H}$ del complejo de inclusión L1-La· $\beta$-CD (figura 4c), se observan las señales del ligando $\mathrm{Na}(4-C l c i n n)$, así como las señales de la $\beta$-CD. Para la $\beta$-CD se tiene a campo alto, superpuestas con la señal del agua, las señales correspondientes a los multipletes del protón $\mathbf{b}$ en $3.30 \mathrm{ppm}$ y el $\mathbf{d}$ en $3.37 \mathrm{ppm}$, luego el multiplete para el protón c entre 3.66-3.62 ppm superpuesto con el multiplete de los protones f y el multiplete del protón e entre 3.58-3.55 ppm, el protón a se observa a 4.83 ppm como doblete. Para los hidroxilos se tienen tres señales, la primera a campo alto perteneciente al OH-f en 4.44 ppm observándose como un triplete, un singlete que corresponde a la señal de $\mathbf{O H}-\mathbf{c}$ en $5.72 \mathrm{ppm}$ y un doblete a $5.77 \mathrm{ppm}$ correspondiente a la señal de $\mathbf{O H}-\mathbf{b}$ desplazado a campo bajo por el efecto desprotector del enlace glucosídico.

En la tabla 2 se comparan las señales obtenidas de los RMN ${ }^{1} \mathrm{H}$ de las figuras 3c, 3d, 4c y 25S. De acuerdo a los desplazamientos químicos (ppm), obtenidos para los diferentes compuestos, se puede proponer la estructura que se observa en la figura 2 como la obtenida para los complejos de inclusión sintetizados, de esta forma la cavidad de menor diámetro de la $\beta$-CD estaría interactuando con el enlace $\alpha, \beta$-insaturado del $\mathrm{Na}$ (4-Clcinn), ya que el protón 1' sufre un mayor desplazamiento a campo bajo por la presencia de un grupo electroatractor que pueden ser los hidroxilos secundarios de la $\beta-C D[26,27]$.

Por otro lado, se observa el desplazamiento del protón 2 a campo alto, lo que sugiere que el campo magnético no interactúa con la misma intensidad debido a la posible formación del enlace de hidrógeno entre el protón $\mathbf{c}$ de la $\beta-\mathrm{CD}$ y el protón 2 del $\mathrm{Na}$ (4-Clcinn). Finalmente, se observa que el protón 3 se desplaza a campo bajo por la presencia de los hidroxilos primarios de la $\beta$-CD.

Tabla 2. Comparación de los desplazamientos químicos (ppm) del RMN 1H de L1, L1-La, L1-La· $\beta$-CD y $\beta$-CD.

\begin{tabular}{|c|c|c|c|c|c|c|c|c|c|}
\hline Protón & 3 & 2 & 1 ' & 2 & & & & & \\
\hline $\mathbf{L}_{1}$ & 7.58 & 7.42 & 7.27 & 6.50 & & & & & \\
\hline $\mathbf{L}_{1} \mathbf{L a}$ & 7.55 & 7.38 & 7.34 & 6.46 & & & & & \\
\hline $\mathrm{L}_{1} \mathbf{L a} \beta-\mathrm{CD}$ & 7.61 & 7.34 & 7.42 & 6.43 & & & & & \\
\hline Protón & $\mathbf{a}$ & b & c & d & e & f & b-OH & $\mathrm{c}-\mathrm{OH}$ & $\mathrm{f}-\mathrm{OH}$ \\
\hline $\mathrm{L}_{1} \mathbf{L a} \beta-\mathrm{CD}$ & 4.83 & 3.30 & $\begin{array}{c}3.66- \\
3.62\end{array}$ & 3.37 & $\begin{array}{c}3.58- \\
3.55\end{array}$ & $\begin{array}{c}3.66- \\
3.62\end{array}$ & 5.72 & 5.77 & 4.44 \\
\hline$\beta-\mathbf{C D}$ & 4.83 & $\begin{array}{c}3.32- \\
3.30\end{array}$ & $\begin{array}{c}3.66- \\
3.61\end{array}$ & 3.37 & $\begin{array}{c}3.58- \\
3.55\end{array}$ & $\begin{array}{c}3.66- \\
3.61\end{array}$ & 5.67 & 5.72 & 4.44 \\
\hline
\end{tabular}

Además de los análisis espectroscópicos, se realizó un estudio termogravimétrico de los complejos sintetizados para determinar el contenido de moléculas de agua, la variación del punto de fusión y los productos de descomposición que se forman a lo largo del análisis termogravimétrico, permitiendo proponer la estequiometría de los complejos de inclusión. Se ha reportado que el análisis termogravimétrico de la $\beta$-CD presenta cuatro eventos térmicos: deshidrata- 
ción, transición de fase, fusión [28] y finalmente apertura de los anillos de $\beta-\mathrm{CD}$, seguido de la descomposición de la glucopiranosa produciendo mayoritariamente dióxido de carbono, agua y furanos [29]. En la figura 4d se puede observar que la $\beta$-CD empleada al calentarse se deshidrató perdiendo $10.57 \%$ de masa lo que equivale a 7 moléculas de agua, presenta la transición de fase a $226{ }^{\circ} \mathrm{C}$, funde a $305.4{ }^{\circ} \mathrm{C}$ y luego se descompone. Al comparar el termograma de la $\beta-\mathrm{CD}$ con el del complejo L1-La $\beta$-CD se destaca que este último pierde $6.08 \%$ de masa en el mismo rango de temperatura para la deshidratación de la $\beta-\mathrm{CD}$, el cambio se atribuye a un menor número de moléculas de agua en el complejo de inclusión (ver tabla 3); este cambio puede deberse a que el complejo lantánido al ingresar a la cavidad interna de la $\beta-C D$ desplaza las moléculas de agua de hidratación que tenía inicialmente.

Tabla 3. Resultados de la descomposición térmica en atmósfera de nitrógeno de los complejos lantánidos y de inclusión con La (III), Ce (III), Sm (III) e Yb (III).

\begin{tabular}{|c|c|c|c|c|}
\hline \multirow{2}{*}{ Compuesto } & \multirow{2}{*}{$\begin{array}{l}\text { Picos DTG } \\
\left({ }^{\circ} \mathrm{C}\right)\end{array}$} & \multicolumn{2}{|c|}{ Pérdida de masa (\%) } & \multirow{2}{*}{ Productos } \\
\hline & & Exp. & Calc. & \\
\hline \multirow{3}{*}{$\mathrm{LaL1} \cdot 2.3 \mathrm{H}_{2} \mathrm{O}$} & 98.1 & 0.85 & 0.87 & $\mathrm{LaL} 1 \cdot 2 \mathrm{H}_{2} \mathrm{O}$ \\
\hline & 277.8 & 5.14 & 5.18 & LaL1 \\
\hline & 398.3 & 33.69 & 32.01 & $\mathrm{La}_{2}\left(\mathrm{CO}_{3}\right)_{3}$ \\
\hline \multirow{2}{*}{$\beta-\mathrm{CD} \cdot 7.5 \mathrm{H}_{2} \mathrm{O}$} & 109.0 & 10.57 & 10.63 & $\beta-C D$ \\
\hline & 312.3 & 63.62 & 63.49 & $4 \times$ glucopiranosa \\
\hline \multirow[b]{2}{*}{$\begin{array}{r}\text { L1-La' } \beta- \\
\text { CD'14.5H } 20\end{array}$} & 96.6 & 6.08 & 5.99 & L1-La' $\beta-C D$ \\
\hline & 320.2 & 60.85 & 62.43 & $\begin{array}{c}6 \times \text { glucopiranosa } \\
+\mathrm{La}_{2}\left(\mathrm{CO}_{3}\right)_{3}\end{array}$ \\
\hline \multirow[b]{2}{*}{ L1-Ce' $\beta-C D \cdot 7 \mathrm{H}_{2} \mathrm{O}$} & 91.7 & 3.00 & 2.98 & $\mathrm{~L} 1-\mathrm{Ce} \cdot \beta-\mathrm{CD}$ \\
\hline & 313.7 & 76.59 & 75.53 & $\begin{array}{c}3 \times \text { glucopiranosa } \\
+\mathrm{Ce}_{2}\left(\mathrm{CO}_{3}\right)_{3}\end{array}$ \\
\hline \multirow{2}{*}{$\begin{array}{r}\mathrm{L} 1-\mathrm{Sm} \cdot \beta- \\
\mathrm{CD} \cdot 18 \mathrm{H}_{2} \mathrm{O}\end{array}$} & 101.6 & 7.30 & 7.32 & $\mathrm{~L} 1-\mathrm{Sm} / \beta-\mathrm{CD}$ \\
\hline & 288.4 & 56.88 & 57.53 & $\begin{array}{l}7 \times \text { glucopiranosa } \\
+\mathrm{Sm}_{2}\left(\mathrm{CO}_{3}\right)_{3}\end{array}$ \\
\hline \multirow[b]{2}{*}{$L 1-Y b \cdot \beta-C D \cdot 23 H_{2} O$} & 99.3 & 8.88 & 9.12 & $\mathrm{~L} 1-\mathrm{Yb} \cdot \beta-\mathrm{CD}$ \\
\hline & 300.2 & 62.60 & 61.03 & $\begin{array}{c}6 \times \text { glucopiranosa } \\
+\mathrm{Yb}_{2}\left(\mathrm{CO}_{3}\right)_{3}\end{array}$ \\
\hline \multirow[b]{2}{*}{$\mathrm{L} 2-\mathrm{Ce} \cdot \beta-\mathrm{CD} \cdot 21 \mathrm{H}_{2} \mathrm{O}$} & 92.3 & 8.40 & 8.48 & L2-Ce' $\beta-\mathrm{CD}$ \\
\hline & 308.9 & 62.95 & 62.20 & $\begin{array}{c}6 \times \text { glucopiranosa } \\
+\mathrm{Ce}_{2}\left(\mathrm{CO}_{3}\right)_{3}\end{array}$ \\
\hline \multirow{2}{*}{$\begin{array}{l}\mathrm{L} 2-\mathrm{Sm} \cdot \beta- \\
\mathrm{CD} \cdot 17 \mathrm{H}_{2} \mathrm{O}\end{array}$} & 101.4 & 7.01 & 6.96 & $\mathrm{~L} 2-\mathrm{Sm} \cdot \beta-\mathrm{CD}$ \\
\hline & 311.6 & 67.47 & 66.20 & $\begin{array}{c}5 \times \text { glucopiranosa } \\
+\mathrm{Sm}_{2}\left(\mathrm{CO}_{3}\right)_{3}\end{array}$ \\
\hline \multirow{2}{*}{$\begin{array}{r}L 2-Y b \cdot \beta- \\
C D \cdot 21 H_{2} O\end{array}$} & 106.2 & 8.42 & 8.42 & $\mathrm{~L} 2-\mathrm{Yb} \cdot \beta-\mathrm{CD}$ \\
\hline & 312.0 & 65.68 & 65.29 & $\begin{array}{c}5 \times \text { glucopiranosa } \\
+\mathrm{Yb}_{2}\left(\mathrm{CO}_{3}\right)_{3}\end{array}$ \\
\hline
\end{tabular}

Además de observar el primer evento térmico (deshidratación), se observaron varios cambios para el punto de fusión en los termogramas de las figuras 34S-55S (información suplementaria), el primero de ellos es que la mezcla física (L1-La/ $\beta$ CD) funde a $306.0^{\circ} \mathrm{C}$, lo que permite suponer la existencia de algún tipo de interacción, y el segundo es que el complejo L1-La· $\beta$-CD funde y se 
descompone entre $290-340{ }^{\circ} \mathrm{C}$ en un solo paso. Este patrón se conserva en los demás complejos de inclusión sintetizados, por lo cual se puede suponer que mejoró la estabilidad térmica de los compuestos [30].

Para evaluar la cristalinidad de los sólidos obtenidos, se realizó un estudio por DRX. En las figuras 30S-33S (información suplementaria) se puede observar y comparar los difractogramas de los complejos L1-La y L1-La- $\beta$-CD, la $\beta$-CD y la mezcla física (L1-La/ $\beta-C D)$. En el análisis de los DRX obtenidos es claro que se presentan diferentes perfiles difractográficos; para el complejo L1-La se observan picos característicos a $7.90^{\circ}$, $12.00^{\circ}$ y $24.40^{\circ}(2 \theta)$ y para la $\beta-C D$ a $10.60^{\circ}$ y $12.40^{\circ}(2 \theta)$, mientras que la mezcla física pasa de 43 picos a 26 en el complejo de inclusión. La obtención de un nuevo patrón de difracción evidencia que L1-La· $\beta$-CD es un compuesto totalmente diferente a la mezcla, solo se conservan los picos a $8.10^{\circ}$ y $12.01^{\circ}(2 \theta)$ de L1-La y algunos picos de la $\beta-C D$ aunque con menor intensidad a la inicial, este resultado permite inferir la pérdida de cristalinidad al incluir el complejo lantánido en la $\beta$-CD [25].
Mediante estudios de UV-Vis se encontró que la longitud de onda de máxima absorbancia en el caso de los complejos con L1 fue a $274 \mathrm{~nm}$ y con L2 fue a $286 \mathrm{~nm}$, variación generada por efecto del sustituyente en el anillo aromático. Para los compuestos carbonílicos y aromáticos se observa una banda entre 220-250 nm (transiciones electrónicas $\pi \rightarrow \pi^{*}$ ) debido a la conjugación entre ambos grupos y no a la superposición de los espectros independientes del anillo aromático y del ácido carboxílico [31]. En los complejos de inclusión se observa que la intensidad de la banda y el coeficiente de absortividad para la transición $\pi \rightarrow \pi^{*}$ disminuyen, esto puede deberse a que la luz incidente interactúa menos con el sistema conjugado y no permite que se den de igual forma las transiciones electrónicas (ver figuras información suplementaria 56S-69S). Por medio de espectroscopía UV-Vis también fue posible determinar la solubilidad de los complejos obtenidos, se prepararon soluciones sobresaturadas y se confirmó un aumento en la intensidad de las bandas dependiente de la concentración de cada compuesto, los resultados se observan en la Tabla 4.

Tabla 4. Solubilidad en agua a temperatura ambiente de los complejos lantánidos libres e incluidos parcialmente.

\begin{tabular}{|c|c|c|c|}
\hline Compuesto & Solubilidad (mg/mL) & Compuesto & Solubilidad $(\mathrm{mg} / \mathrm{mL})$ \\
\hline L1-Ce & 0.17 & L1-Ce' $\beta-C D$ & 3.36 \\
\hline L1-Sm & 0.10 & L1-Sm' $\beta-C D$ & 3.06 \\
\hline L1-Yb & 0.33 & L1-Yb' $\beta-C D$ & 1.70 \\
\hline $\mathrm{L2}-\mathrm{Ce}$ & 0.67 & L2-Ce' $\beta-C D$ & 2.38 \\
\hline L2-Sm & 0.57 & $\mathbf{L 2 - S m} \cdot \beta-\mathbf{C D}$ & 2.97 \\
\hline L2-Yb & 0.26 & $L 2-Y b \cdot \beta-C D$ & 2.42 \\
\hline
\end{tabular}

Los resultados de la caracterización estructural de los complejos permiten proponer que por medio del método de co-precipitación se obtuvo un complejo de inclusión parcial con posible relación estequiométrica 1:3 complejo lantánido: $\beta$-CD, de forma que el enlace $\alpha, \beta$-insaturado del ligando interactúa con los hidroxilos secundarios del anfitrión logrando desplazar las 7 moléculas de agua que se encontraban inicialmente dentro del toroide, además el complejo de inclusión es más estable a la descomposición térmica en comparación al complejo lantánido sin inclusión.

\section{Pruebas antibacterianas}

Para la realización de las pruebas antibacterianas, se utilizaron dos cepas bacterianas gram-positivas (S. aureus ATCC 25923 y S. aureus ATCC 29213), y cuatro cepas bacterianas gram-negativas (E. coli ATCC 25922, P. aeruginosa ATCC 27853, S. Typhimurium ATCC 14028 у K. pneumoniae ATCC BAA-2146). Se evaluaron los cloruros de lantánido correspondientes y se encontró que no presentaban actividad antibacteriana en las concentraciones evaluadas $(4000-7,8 \mu \mathrm{g} /$ $\mathrm{mL}$ ), sin embargo, los complejos lantánidos pre- 
sentaron menor CMI al compararlos con el resultado para L1, esto demuestra el efecto sinérgico entre el metal y el ligando. Esta disminución en la CMI o mayor actividad de los complejos puede ser a causa de la deslocalización que se produce de los electrones $\pi$ lo cual aumenta el carácter lipofílico de la molécula permitiendo que penetre más fácilmente las membranas lipídicas [32,33].

En la tabla 5 se presentan los resultados de las pruebas antibacterianas con los compuestos seleccionados. Al comparar los valores de CMI obtenidos para las bacterias gram-positivas y gram-negativas, no se observó un patrón que permita relacionar la actividad antimicrobiana de los complejos con la funcionalidad de la membrana celular de las bacterias, por lo que estos resultados sugieren descartar la posibilidad de que los compuestos estudiados empleen un mecanismo de acción por alteración de la membrana citoplasmática, que es uno de los cinco mecanismos de acción antibacteriana reportados en la literatura [34]. Adicionalmente, se observó que la CMI para los complejos de inclusión es menor en comparación a la CMI para los complejos lantánidos, esto puede deberse al incremento de la solubilidad en el medio, abriendo la posibilidad de ser aplicado en el diseño racional de nuevos metalofármacos que permitan aumentar su efecto biológico; sin embargo, los complejos evaluados no tuvieron la misma acción antibacteriana en todas las cepas. De las cepas evaluadas, podemos concluir que la que presenta mayor resistencia a la acción antibacteriana de los complejos evaluados es la $P$. aureginosa, ningún complejo fue activo a la mayor concentración evaluada. En la literatura se ha reportado que esta cepa presenta mayor resistencia a antibióticos sin ser claro el mecanismo de defensa de la misma [35].

Tabla 5. Actividad antibacteriana de los complejos con ligando L1

\begin{tabular}{|c|c|c|c|c|c|c|}
\hline \multirow[b]{2}{*}{ Comp. } & \multicolumn{6}{|c|}{$C M I(\mathrm{~mol} / \mathrm{L})$} \\
\hline & $\begin{array}{c}E . \text { coli } \\
\text { ATCC } 25922\end{array}$ & $\begin{array}{c}\text { S. aureus } \\
\text { ATCC } 25923\end{array}$ & $\begin{array}{c}\text { S. aureus } \\
\text { ATCC } 29213\end{array}$ & $\begin{array}{c}\text { P. aureginosa } \\
\text { ATCC } 27853\end{array}$ & $\begin{array}{c}\text { S. Typhimu- } \\
\text { rium ATCC } \\
14028\end{array}$ & $\begin{array}{c}\text { K. pneumoniae } \\
\text { ATCC BAA-2146 }\end{array}$ \\
\hline$\beta-C D$ & $3.5 \times 10^{-3}$ & $>3.5 \times 10^{-3}$ & $>3.5 \times 10^{-3}$ & $3.5 \times 10^{-3}$ & $3.5 \times 10^{-3}$ & $3.5 \times 10^{-3}$ \\
\hline L1 & $2.2 \times 10^{-2}$ & $5.5 \times 10^{-3}$ & $2.2 \times 10^{-2}$ & $2.2 \times 10^{-2}$ & $1.1 \times 10^{-2}$ & $2.2 \times 10^{-2}$ \\
\hline L1-Ce & $>2.9 \times 10^{-3}$ & $2.9 \times 10^{-3}$ & $2.9 \times 10^{-3}$ & $>2.9 \times 10^{-3}$ & $2.9 \times 10^{-3}$ & $>2.9 \times 10^{-3}$ \\
\hline L1-Sm & $>2.8 \times 10^{-3}$ & $>2.8 \times 10^{-3}$ & $2.8 \times 10^{-3}$ & $>2.8 \times 10^{-3}$ & $2.8 \times 10^{-3}$ & $>2.8 \times 10^{-3}$ \\
\hline L1-Yb & $2.7 \times 10^{-3}$ & $2.7 \times 10^{-3}$ & $2.7 \times 10^{-3}$ & $>2.7 \times 10^{-3}$ & $2.7 \times 10^{-3}$ & $2.7 \times 10^{-3}$ \\
\hline $\begin{array}{l}\mathrm{L1-Ce} \beta- \\
\quad C D\end{array}$ & $>9.8 \times 10^{-4}$ & $>9.8 \times 10^{-4}$ & $>9.8 \times 10^{-4}$ & $>9.8 \times 10^{-4}$ & $9.8 \times 10^{-4}$ & $9.8 \times 10^{-4}$ \\
\hline $\begin{array}{l}\text { L1-Sm } \beta- \\
\quad C D\end{array}$ & $>9.7 \times 10^{-4}$ & $>9.7 \times 10^{-4}$ & $>9.7 \times 10^{-4}$ & $>9.7 \times 10^{-4}$ & $9.7 \times 10^{-4}$ & $9.7 \times 10^{-4}$ \\
\hline $\begin{array}{c}\text { L1-Yb' } \beta- \\
\text { CD }\end{array}$ & $>9.7 \times 10^{-4}$ & $>9.7 \times 10^{-4}$ & $9.7 \times 10^{-4}$ & $>9.7 \times 10^{-4}$ & $9.7 \times 10^{-4}$ & $>9.7 \times 10^{-4}$ \\
\hline
\end{tabular}

\section{Interacción con ADN}

Una vez evaluada la actividad antimicrobiana de los complejos sintetizados, se realizaron dos ensayos con el fin de evaluar el tipo de interacción intermolécular de los complejos con la macromolécula de ADN. En el primer ensayo, se estudió por UV-vis la posible interacción de los complejos con ADN de timo de ternera y para la segunda prueba se empleó ADN plasmídico de $E$. coli pBR322 utilizando la técnica de electroforesis. Para estos ensayos fueron seleccionados dos complejos: L1-Sm (3) y L1-Sm· $\beta$-CD (10), los cuales presentaron mayor solubilidad y mayor actividad antibacteriana.

En el ensayo UV-Vis se observó hipercromismo con desplazamiento hacia el rojo cuando se mantuvo constante la concentración de ADN de timo de ternera mientras se aumentaba la concentración de complejo lantánido o del complejo de inclusión (figuras 5a y 5c), mientras que, al aumentar la concentración de ADN, manteniendo constante la concentración de complejo lantánido 


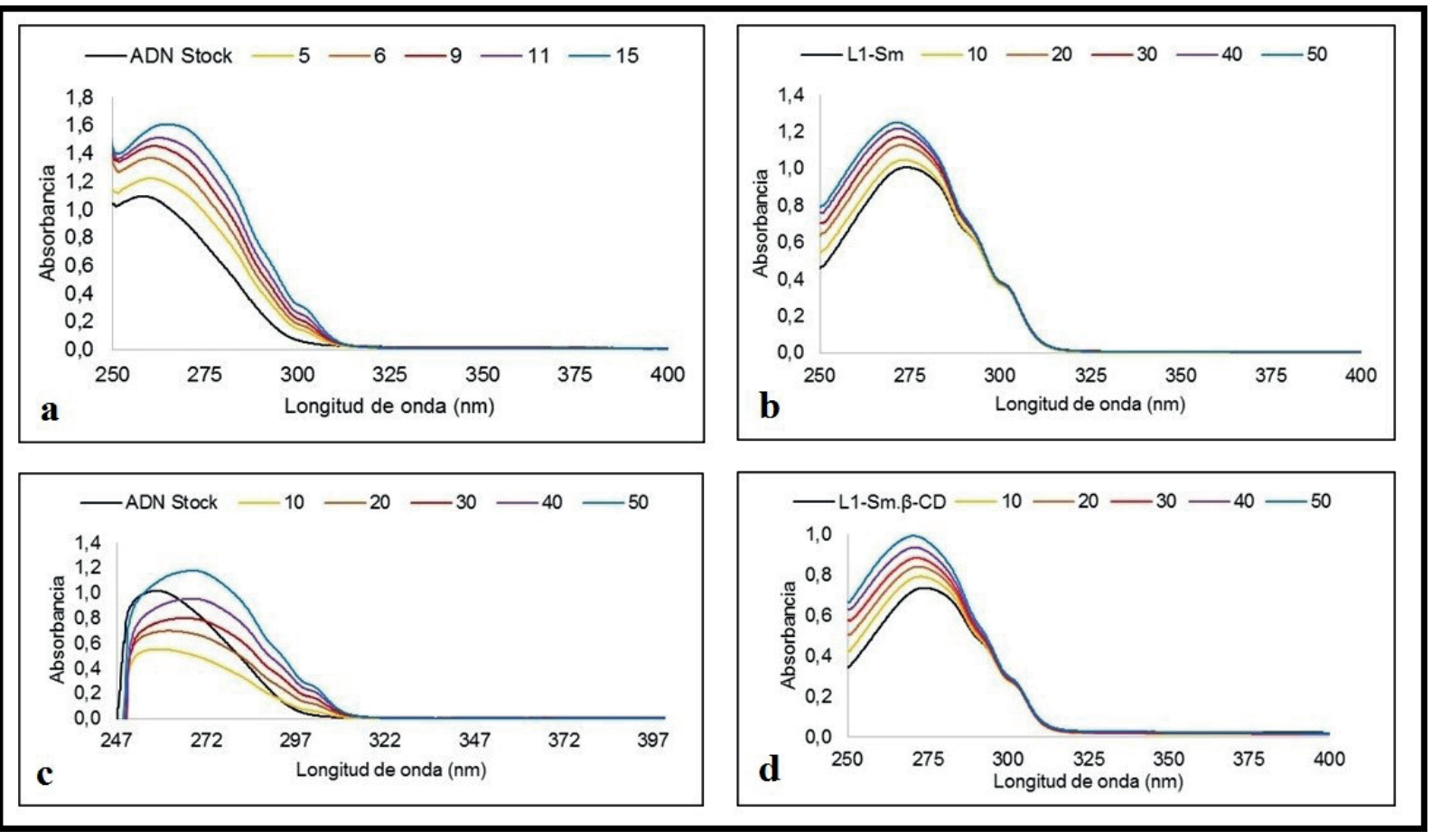

Figura 5. Estudios de interacción: a) L1-Sm a 5-15 $\mu \mathrm{M}$ y concentración constante de ADN de Timo de ternera (153 $\mu \mathrm{M}$ nucleótidos); b) ADN de timo de ternera a 10-50 $\mu \mathrm{M}$ nucleótidos y concentración constante de L1-Sm (20 $\mu \mathrm{M})$. c) L1-Sm· $\beta$-CD a 10-50 $\mu \mathrm{M}$ y concentración constante de ADN de Timo de ternera (153 $\mu \mathrm{M}$ nucleótidos); d)

ADN de timo de ternera a 10-50 $\mu \mathrm{M}$ nucleótidos y concentración constante de complejo de inclusión $(70 \mu \mathrm{M})$.

La intercalación de pequeñas moléculas en la doble hélice del ADN, genera en los espectros UV-Vis dos efectos: hipocromismo y desplazamiento hacia el rojo, lo cual es atribuido al apilamiento de los compuestos entre las bases nitrogenadas que restringen las transiciones electrónicas, algunos ejemplos de intercalantes son el cisplatino, $\mathrm{Ni}(\mathrm{Pirox})_{2}(\mathrm{DMF})_{2}$ y $[\mathrm{Mn}(\mathrm{sal})$ (phen) $)_{2} \mathrm{ClO}_{4}$ [36-38]. De acuerdo a los resultados obtenidos es factible proponer que los complejos evaluados no se intercalan en la molécula de $\mathrm{ADN}$, además, la ausencia de un punto isobéstico claro en el espectro UV-Vis, indica que existe más de un tipo de enlace o interacción en el sistema estudiado. Igualmente, se ha reportado que la unión electrostática generada por la interacción entre el centro metálico y los grupos fosfatos de las hebras de ADN puede generar hipercromismo [39], en donde la hidrofobicidad del ligando y el tamaño del complejo lo afectan directamente [40].
Para el segundo ensayo se evaluó la posible interacción de los complejos con el ADN de un organismo procariota (E. coli). Para esto se realizaron experimentos de electroforesis empleando ADN plasmídico, el cual se caracteriza por tener tres tipos de conformación: lineal, circular relajada y superenrrollada. Además, puede poseer genes que le confieren a las bacterias ventajas adaptativas como resistencia a antibióticos, producción de sustancias tóxicas o codificación de enzimas para degradar sustancias químicas. En este caso el ADN plasmídico pBR322 codifica resistencia a la ampicilina y la tetraciclina. En la figura 6 se observa que presenta tres bandas, la primera para la conformación II (circular relajada) mayor a $10000 \mathrm{pb}$, la segunda para la conformación III (lineal) aproximadamente a 5000 pb y por último la tercera para la conformación I (superenrrollada) aproximadamente a $3000 \mathrm{pb}$. 


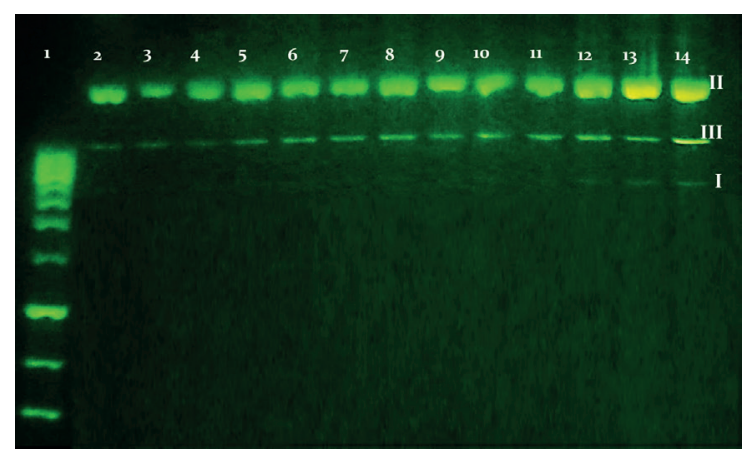

Figura 6. Electroforesis en gel de agarosa 1\% para el ADN plasmídico pBR322 después de 75 minutos de incubación a $37^{\circ} \mathrm{C}$. Carril 1, HyperLadder III Bioline; Carril 2, control de ADN; Carril 3, ADN + 10(10 $\mu \mathrm{M})$; Carril 4, ADN + $10(10 \mu \mathrm{M})+\mathrm{H}_{2} \mathrm{O}_{2}$; Carril 5, ADN + $10(30 \mu \mathrm{M})$; Carril 6, $\mathrm{ADN}+10(30 \mu \mathrm{M})+\mathrm{H}_{2} \mathrm{O}_{2} ;$ Carril 7, $\mathrm{ADN}+10(50 \mu \mathrm{M})$; Carril 8, ADN + 10(50 $\mu \mathrm{M})+\mathrm{H}_{2} \mathrm{O}_{2}$; Carril 9, ADN + $3(10$ $\mu \mathrm{M})$; Carril 10, ADN $+3(10 \mu \mathrm{M})+\mathrm{H}_{2} \mathrm{O}_{2}$; Carril 11, ADN $+3(30 \mu \mathrm{M})$; Carril 12, $\mathrm{ADN}+3(30 \mu \mathrm{M})+\mathrm{H}_{2} \mathrm{O}_{2}$; Carril $13, \mathrm{ADN}+3(50 \mu \mathrm{M})$; Carril 14, $\mathrm{ADN}+3(50 \mu \mathrm{M})+\mathrm{H}_{2} \mathrm{O}_{2}$.

Cabe denotar que no se observó ningún cambio en los carriles 3-12 al compárarlos con el control de ADN, sin embargo en el carril 13 se observa el aumento cualitativo de la intensidad de la banda correspondiente a la forma II, lo que podría indicar que la forma superenrrollada se relaja y adopta mayoritariamente la forma circular, y en el carril 14 disminuye un poco la intensidad de la banda de la forma II y aumenta la intensidad de la banda de la forma III, es decir, que para este último carril podría ocurrir que se desnaturalice un porcentaje del ADN de la forma II aumentando el ADN que se encuentra en forma lineal; algunos autores explican los cambios conformacionales del plásmido debido a que los Ln(III), por sus altos números de coordinación, pueden actuar como catalizadores en la hidrolisis de los enlaces fosfodiéster de las cadenas de ADN y ARN [41]. Se ha reportado que compuestos con iones lantánidos en soluciones acuosas, exhiben características similares a las nucleasas promoviendo la formación de un intermediario que facilita la hidrólisis de los enlaces fosfodiéster de las macromoléculas de ADN y ARN $[42,43]$.

\section{CONCLUSIONES}

Se sintetizó y caracterizó una serie de complejos lantánidos con ligandos cinámicos. De acuerdo a la caracterización vibraciónal y espectroscópica se propone que presentan coordinación bidentada a través de los oxígenos carboxílicos del cinamato y los iones lantánidos. Por medio del método de co-precipitación se obtuvieron los nuevos complejos correspondientes de inclusión parcial y/o asociación, de acuerdo a la caracterización vibraciónal, espectroscópica y térmica, se propone que el complejo sintetizado presenta una estequiometria 1:3 complejo lantánido: $\beta$-CD, donde el enlace $\alpha, \beta$-insaturado del ligando interactúa con los hidroxilos secundarios del anfitrión, la formación de este compuesto aumenta la estabilidad térmica y la solubilidad del complejo lantánido. Los ensayos de actividad antibacteriana permitieron evidenciar en los complejos lantánidos el efecto sinérgico entre el catión lantánido y el ligando cinamato. Además, los complejos de inclusión presentaron disminución en la concentración mínima inhibitoria (CMI) respecto a los complejos lantánidos iniciales, lo cual se podría deber al aumento de la solubilidad de los complejos lantánidos. Los ensayos con ADN permitieron evidenciar su posible interacción con los complejos evaluados, donde el catión lantánido estaría interaccionando electrostáticamente con la cadena de fosfatos del ADN de timo de ternera, a su vez participaría en la relajación de la forma superenrrollada y escisión de la forma circular del ADN plasmídico pBR322 al hidrolizar la cadena de fosfatos.

\section{AGRADECIMIENTOS}

Los autores agradecen a la Universidad del Valle, a Colciencias (110656934339), al Banco de la República (3238) por su financiación para la realización de este proyecto, al Tecnoparque SENA nodo Cali (6377) y Complejo integral de servicios de salud pública "Aníbal Patiño Rodríguez" - Secretaría de Salud Valle del Cauca por el préstamo de sus instalaciones. 


\section{REFERENCIAS}

[1] G. Wright, "Solving the antibiotics crisis", ACS Infect. Dis., vol. 1, no. 2, pp. 80-84, Jan. 2015. http://pubs.acs.org/doi/abs/10.1021/ id500052s.

[2] R. Hamidpour, M. Hamidpour, S. Hamidpour, M. Shahlari, "Cinnamon from the selection of traditional applications to its novel effects on the inhibition of angiogenesis in cancer cells and prevention of Alzheimer's disease, and a series of functions such as antioxidant, anticholesterol, antidiabetes, antibacterial, antifungal, nematicidal, acaracidal, and repellent activities", $J$. Tradit. Complement. Med., vol. 5, no. 2, pp. 66-70, Apr. 2015. https://doi.org/10.1016/j. jtcme.2014.11.008.

[3] Y. Zhang, X. Liu, Y. Wang, P. Jiang, S. Y. Queck, "Antibacterial activity and mechanism of cinnamon essential oil against Escherichia coli and Staphylococcus aureus", Food Control, vol. 59, pp. 282289, Jan. 2016. https://doi.org/10.1016/j. foodcont.2015.05.032.

[4] C. Letizia, J. Cocchiara, A. Lapczynski, J. Lalko, A. Api, "Fragrance material review on cinnamic acid", Food Chem. Toxicol., vol. 43, no. 6, pp. 925-943, Jun. 2005. https:// doi.org/10.1016/j.fct.2004.09.015.

[5] B. Narasimhan, D. Belsare, D. Pharande, V. Mourya, A. Dhake, "Esters, amides and substituted derivatives of cinnamic acid: synthesis, antimicrobial activity and QSAR investigations", Eur. J. Med. Chem., vol. 39, no. 10 , pp. $827-834$. Oct. 2004. https://doi. org/10.1016/j.ejmech.2004.06.013.

[6] P. Sharma, "Cinnamic acid derivatives: A new chapter of various pharmacological activities". J. Chem. Pharm. Res., vol. 3, no. 2, pp. 403-423. Jan. 2011. http://www. jocpr.com/abstract/cinnamic-acid-derivatives-a-new-chapter-of-various-pharmacological-activities-712.html.
[7] S. Venkateswarlu, M. Ramachandra, A. Krishnaraju, G. Trimurtulu, G. Subbaraju, "Antioxidant and antimicrobial activity evaluation of polyhydroxycinnamic acid ester derivatives", Indian J. Chem., vol. 45B, pp. 252-257, Jan. 2006. http://hdl.handle. net/123456789/6188.

[8] A. Chambel, C. Viegas, I. Sá-Correia, "Effect of cinnamic acid on the growth and on plasma membrane 1H-ATPase activity Saccharomyces cerevisiae", Inter. J. Food Microbiol., vol. 50, no. 3, pp. 173-179, Sep. 1999. https://doi.org/10.1016/ S0168-1605(99)00100-2.

[9] S. Adisakwattana, K. Sookkongwaree, S. Roengsumran, A. Petsom, N. Ngamrojnavanich, W. Chavasiri, D. Deesamer, S. Yibchok, "Structure-activity relationships of trans-cinnamic acid derivatives on a-glucosidase inhibition", Bioorg. Med. Chem. Lett., vol. 14, no. 11, pp. 2893-2896, Jun. 2004. https://doi.org/10.1016/j.bmcl.2004.03.037.

[10] S. Carvalho, E. Silva, M. Souza, M. Lourenc, F. Vicenteb, "Synthesis and antimycobacterial evaluation of new trans-cinnamic acid hydrazide derivatives", Bioorg. Med. Chem. Lett., vol. 18, no. 2, pp. 538-541, Jan. 2008. https://doi.org/10.1016/j.bmcl.2007.11.091.

[11] F. Bisogno, L. Mascoti, C. Sanchez, F. Garibotto, F. Giannini, M. Kurina-Sanz, R. Enriz, "Structure-antifungal activity relationship of cinnamic acid derivatives", J. Agr. Food Chem., vol. 55, no. 26, pp. 10635-10640, Nov. 2007. http://pubs.acs. org/doi/abs/10.1021/jf0729098.

[12] N. J. Bello-Vieda, H. F. Pastrana, M. F. Garavito, A. G. Ávila, A. M. Celis, A. Muñoz-Castro, S. Restrepo, J. J. Hurtado, "Antibacterial Activities of Azole Complexes Combined with Silver Nanoparticles", Molecules, vol. 23, no. 2, pp. 361, 1-17, Feb. 2018. https://doi. org/10.3390/molecules23020361.

[13] K. F. Castillo, N. J. Bello-Vieda, N. G. Nuñez-Dallos, H. F. Pastrana, A. M. Celis, S. Restrepo, J. J. Hurtado, A. G. Ávila, 
"Metal Complex Derivatives of Azole: a Study on Their Synthesis, Characterization, and Antibacterial and Antifungal Activities", J. Braz. Chem. Soc., vol. 27, no. 12, pp. 2334-2347, Dec. 2016. http://dx.doi. org/10.5935/0103-5053.20160130.

[14] N. K. Singh, S. B. Singh, D. K. Singh, V. B. Chauhan, "Synthesis, characterization and biological properties of N-nicotinoyl-N'-thiobenzoyl-hydrazine complexes of cobalt(II), nickel(II), copper(II) and zinc(II), Indian J. Chem., vol. 42A, pp. 2767-2771, Nov. 2003. http://nopr.niscair.res. in/bitstream/123456789/20791/1/IJCA\%20 42A(11)\%202767-2771.pdf.

[15] A. Aragon-Muriel, D. Polo-Cerón, "Synthesis, characterization, thermal behavior, and antifungal activity of $\mathrm{La}$ (III) complexes with cinnamates and 4-methoxyphenylacetate", J. Rare Earths, vol. 31, no. 11, pp. 1106-1113, Nov. 2013. https://doi.org/10.1016/ S1002-0721(12)60412-8.

[16] A. Aragon-Muriel, Y. Upegui, J. A. Muñoz, S. M. Robledo, D. Polo-Ceron, "Synthesis, characterization and biological evaluation of rare earth complexes against tropical diseases Leishmaniasis, Malaria and Trypanosomiasis", Avances en Química, vol. 11, no. 2, pp. 53-61, Aug. 2016. http://erevistas. saber.ula.ve/index.php/avancesenquímica/ article/view/7863/7806.

[17] E. M. Martin Del Valle, "Cyclodextrins and their uses: a review". Process Biochem., vol. 39, no. 9, pp. 1033-1046, May 2004. https:// doi.org/10.1016/S0032-9592(03)00258-9.

[18] E. Santos, J. Kamimura, L. Hill, C. Gomes, "Characterization of carvacrol beta-cyclodextrin inclusion complexes as delivery systems for antibacterial and antioxidant applications", Food Sci. Technol., vol. 60, no. 1, pp. 583-592, Jan. 2015. https://doi. org/10.1016/j.lwt.2014.08.046.

[19] K. Uekama, F. Hirayama, T. Irie, "Cyclodextrin Drug Carrier Systems", Chem. Rev., vol. 98 , no. 5, pp. 2045-2076, Jul. 1998. http:// pubs.acs.org/doi/abs/10.1021/cr970025p.

[20] C. Demicheli, R. Ochoa, J. Da Silva, C. Falcao, B. Rossi-Bergmann, A. De Melo, R. Sinisterra, F. Frézard, "Oral Delivery of Meglumine Antimoniate- $\beta$-Cyclodextrin Complex for Treatment of Leishmaniasis", Antimicrob. Agents Chemother., vol. 48, no. 1, pp. 100-103, Jan. 2004. https://dx.doi. org/10.1128\%2FAAC.48.1.100-103.2004.

[21] G. Deacon, M. Forsyth, P. Junk, S. Leary, W. Lee, "Synthesis and characterisation of rare earth complexes supported by para-substituted cinnamate ligands", Z. Anorg. Allg. Chem., vol. 635, no. 6-7, pp. 833-839, May 2009. http://dx.doi.org/10.1002/zaac. 200801379.

[22] Performance Standards for Antimicrobial Disk and Dilution Susceptibility Tests for Bacterial Isolated from Animals, CLSI M31-A3. 3 ed., 2008.

[23] G. Deacon, F. Huber, R. Phillips, "Diagnosis of the nature of carboxylate coordination from the direction of shifts of carbón-oxygen stretching frequencies", Inorg. Chim. Acta., vol. 104, no. 1, pp. 41-45, Oct. 1985. https:// doi.org/10.1016/S0020-1693(00)83783-4.

[24] A. Aragón-Muriel, M. Camprubi, E. Gonzalez, A. Salinas, A. Rodriguez, S. Gomez, D. Polo-Cerón, "Dual investigation of lanthanide complexes with cinnamate and phenylacetate ligands: study of the cytotoxic properties and the catalytic oxidation of styrene", Polyhedron, vol. 80, pp. 117-128, Sep. 2014. https://doi.org/10.1016/j. poly.2014.02.040.

[25] N. Roik, L. Belyakova, "Infrared spectroscopy, $\mathrm{x}$-ray diffraction and thermal analysis studies of solid b-cyclodextrin - para-aminobenzoic acid inclusion complex", PCSS, vol. 12, no. 1, pp. 168-173, 2011. http:// www.pu.if.ua/inst/phys_che/start/pcss/ vol12/1201-26.pdf 
[26] A. Kokkinou, S. Makedonopoulou, D. Mentzafos, "The cristal structure of the 1:1 complex of $\beta$-cyclodextrin with trans-cinnamic acid", Carbohydr. Res., vol. 328, no. 2, pp. 135-140, Sep. 2000. https://doi.org/10.1016/ S0008-6215(00)00091-4.

[27] H. Schneider, F. Hacket, V. Rüdiger, I. Ikeda, "NMR studies of cyclodextrins and cyclodextrin complexes", Chem. Rev., vol. 98, no. 5, pp. 1755-1786, Jul. 1998. http:// pubs.acs.org/doi/abs/10.1021/cr970019t.

[28] F. Giordano, C. Novak, J. Moyano, “Thermal analysis of cyclodextrins and their inclusion compounds", Thermochim. Acta, vol. 380, no. 2, pp. 123-151, Dec. 2001. https://doi. org/10.1016/S0040-6031(01)00665-7.

[29] K. Chandrul, "Role of Macromolecules in Chromatography: Cyclodextrines", J. Chem. Pharm. Res., vol. 3, no. 6, pp. 822-828, 2011. http://www.jocpr.com/articles/role-of-macromolecules-in-chromatography-cyclodextrines.pdf

[30] T. Pijpers, V. Mathot, B. Goderis, R. Scherrenberg, E. Van der Vegte, "High-Speed Calorimetry for the Study of the Kinetics of (De)vitrification, Crystallization, and Melting of Macromolecules", Macromolecules, vol. 35, no. 9, pp. 3601-3613, Mar. 2002. http://pubs.acs.org/doi/abs/10.1021/ ma011122u? journalCode $=$ mamobx .

[31] R. Abu-Eittah, M. Khedr, M. Goma, W. Zordok, "The structure of cinnamic acid and cinnamoyl azides, a unique localized p system: the electronic spectra and DFT-treatment", Int. J. Quantum. Chem., vol. 112, no. 5, pp. 1256-1272, Mar. 2012. http://dx.doi.org/10.1002/qua.23120.

[32] A. Essawy, M. Afifi, H. Moustafa, S. El-Medani, "DFT calculations, spectroscopic, thermal analysis and biological activity of $\mathrm{Sm}(\mathrm{III})$ and $\mathrm{Tb}$ (III) complexes with 2-aminobenzoic and 2-amino-5-chloro-benzoic acids", Spectrochim. Acta A., vol. 131, pp. 388-397, Oct. 2014. https://doi.org/10.1016/j. saa.2014.04.134.
[33] T. Abbs, A. Pearl, B. Rosy, "Synthesis, characterization, cytotoxicity, DNA cleavage and antimicrobial activity of homodinuclear lanthanide complexes of phenylthioacetic acid", J. Rare Earths, vol. 31, no. 10, pp. 1009-1016. Oct. 2013. https://doi.org/10.1016/ S1002-0721(13)60022-8.

[34] J. Calvo, L. Martínez-Martínez, "Mecanismo de acción de los antimicrobianos", Enferm. Infecc. Microbiol. Clin., vol. 27, no. 1, pp. 44-52, Jan. 2009. http://dx.doi. org/10.1016/j.eimc.2008.11.001.

[35] A. Deredjian, C. Colinon, S. Brothier, S. Favre-Bonte, B. Cournoyer, S. Nazaret, "Antibiotic and metal resistance among hospital and outdoor strains of Pseudomonas aeruginosa", Res. Microbiol., vol. 162, no. 7, pp. 689-700, Sep. 2011. https://doi. org/10.1016/j.resmic.2011.06.007.

[36] K. Suntharalingam, O. Mendoza, A. Duarte, D. Mann, R. Vilar, "A platinum complex that binds non-covalently to DNA and induces cell death via a different mechanism than cisplatin", Metallomics., vol. 5, pp. 514-523, Feb. 2013. https://doi.org/10.1039/ C3MT20252F.

[37] Y. Sun, F. Dong, D. Wang, Y. Lib, “Crystal Structure, Supramolécular Self-Assembly and Interaction with DNA of a Mixed Ligand Manganese(II) Complex", J. Braz. Chem. Soc., vol. 22, no. 6, pp. 10891095, Jun. 2011. http://dx.doi.org/10.1590/ S0103-50532011000600013.

[38] N. Sohrabi, "Binding and uv/vis spectral investigation of interaction of ni(ii) piroxicam complex with calf thymus deoxyribonucleic acid (Ct-DNA): a thermodynamic approach", J. Pharm. Sci. \& Res., vol. 7, no. 8, pp. 533-537, Aug. 2015. http://www. jpsr.pharmainfo.in/Documents/Volumes/ vol7Issue08/jpsr07081507.pdf

[39] A. Jamali, A. Tavakoli, J. Nazhad, "Analytical overview of DNA interaction with Morin and its metal complexes", Eur. Food Res. Technol., vol. 235, no. 3, pp. 
367-373, Sep. 2012. https://doi.org/10.1007/ s00217-012-1778-8.

[40] A. Sigel, H. Sigel, R. Sigel, Interplay between metal ions and nucleic acids. New York: Springer, 2012.

[41] A. Kresel, J. Lisowski, "Enantioselective cleavage of supercoiled plasmid DNA catalyzed by chiral macrocyclic lanthanide(III) complexes", J. Inorg. Biochem., vol. 107, no. 1, pp. 1-5, Feb. 2012. https://doi.org/10.1016/j. jinorgbio.2011.10.011.
[42] M. Komiyama, N. Takeda, H. Shigekawa, "Hydrolysis of DNA and RNA by lanthanide ions: mechanistic studies leading to new applications", Chem. Commun., vol. 16, pp. 1443-1451, 1999. https://doi.org/10.1039/ A901621J.

[43] S. Tabassum, G. Sharma, F. Arjmand, "New modulated design and synthesis of chiral $\mathrm{CuII} / \mathrm{SnIV}$ bimetallic potential anticancer drug entity: In vitro DNA binding and pBR322 DNA cleavage activity", Spectrochim. Acta Part A., vol. 90, pp. 208-217, May 2012. https://doi.org/10.1016/j. saa.2012.01.020. 
